GLOBAL WATER PATHOGEN PROJECT

PART THREE. SPECIFIC EXCRETED PATHOGENS: ENVIRONMENTAL AND EPIDEMIOLOGY ASPECTS

\title{
TOXOPLASMA GONDII
}

\author{
Lilian Bahia-Oliveira \\ Federal University of Rio de Janeiro \\ Rio de Janeiro, Brazil \\ Jorge Gomez-Marin \\ Universidad del Quindio \\ Armenia, Colombia

\section{Karen Shapiro} \\ University of California, Davis \\ Davis, United States
}




\section{Copyright:}

\section{cc) (1) (2) \\ BY SA}

This publication is available in Open Access under the Attribution-ShareAlike 3.0 IGO (CC-BY-SA 3.0 IGO) license (http://creativecommons.org/licenses/by-sa/3.0/igo). By using the content of this publication, the users accept to be bound by the terms of use of the UNESCO Open Access Repository (http://www.unesco.org/openaccess/terms-use-ccbysa-en).

\section{Disclaimer:}

The designations employed and the presentation of material throughout this publication do not imply the expression of any opinion whatsoever on the part of UNESCO concerning the legal status of any country, territory, city or area or of its authorities, or concerning the delimitation of its frontiers or boundaries. The ideas and opinions expressed in this publication are those of the authors; they are not necessarily those of UNESCO and do not commit the Organization.

\section{Citation:}

Bahia-Oliveira, L., Gomez-Marin, J., and Shapiro, K. (2017). Toxoplasma gondii. In: J.B. Rose and B. Jiménez-Cisneros (eds), Water and Sanitation for the 21st Century: Health and Microbiological Aspects of Excreta and Wastewater Management (Global Water Pathogen Project). (R. Fayer and W. Jakubowski (eds), Part 3: Specific Excreted Pathogens: Environmental and Epidemiology Aspects - Section 3: Protists), Michigan State University, E. Lansing, MI, UNESCO. https://doi.org/10.14321/waterpathogens.37

Acknowledgements: K.R.L. Young, Project Design editor; Website Design: Agroknow (http://www.agroknow.com)

Last published: September 8, 2017 


\section{Summary}

Toxoplasma gondii is one of the most common zoonotic parasites worldwide. This parasite causes the disease toxoplasmosis, which is a cosmopolitan food and waterborne infection, with an estimated 1 to 2 billion (approximately 30\%) of the world's population infected. Three severe infection sequelae have major health impacts in humans: congenital infection, ocular toxoplasmosis, and cerebral toxoplasmosis in HIV-infected and immunocompromised people. Oocysts are the robust environmental stage of the parasite, and are excreted only in the feces of domestic cats and wild felids. T. gondii oocysts can contaminate soil and water where they can persist under extreme environmental conditions and may remain infective for one or more years. Environmental contamination with oocysts has been documented worldwide, and their persistence under a range of chemical and physical water and sewage treatment processes pose a serious threat to public health. Toxoplasmosis is considered a neglected disease, and is associated with lower socioeconomic status in both developed and developing countries. Sewage is not source of this parasite unless fecal waste of domestic cats are introduced to the sewer system; however oocysts have been detected in sewage, wastewater, and fresh surface water. Thus, waterborne transmission associated with contamination from cat feces is relevant to human public health on a global scale.

\section{Toxoplasma gondii}

\subsection{Epidemiology of the Disease and Pathogen(s)}

\subsection{Global Burden of Disease}

The global burden of toxoplasmosis has been estimated mainly in the context of congenital infection (including both neurologic and ocular/visual sequelae), and also in the context of foodborne disease (Torgerson and Mastroiacovo, 2013, WHO, 2015). In 2013, the global annual incidence of congenital toxoplasmosis was estimated to be 190,100 cases with a 95\% confidence interval (Torgerson and Mastroiacovo, 2013). Integrated metrics that have been employed to estimate the disease burden include qualityadjusted or disability-adjusted life-years (QALYs) or (DALYs), respectively, and the cost of illness (Opsteegh et al., 2015). Globally, the burden of congenital toxoplasmosis was estimated at 1.20 million DALYs with higher burdens in low income countries (Torgerson and Mastroiacovo, 2013), and congenital and acquired infections leading to 1.68 million DALYs (WHO, 2015).

In the United States of America (USA), the annual burden of T. gondii was estimated at 10,964 QALYs, and is the third most important foodborne pathogen after Salmonella enterica and Campylobacter species, in terms of costs of illness at $>\$ 2.9$ billion (Batz et al., 2012). In the Netherlands, among 14 enteric pathogens, T. gondii ranked first with a total burden estimated at 3,620 DALYs, including 1,350 DALYs attributed to acquired infections (Havelaar et al., 2012). It is noteworthy that the burden estimated in the context of foodborne disease is likely underestimated, because it does not account for toxoplasmosis acquired by ingestion of fresh fruits and vegetables, a neglected route of infection due to lack of standardized methods for oocyst detection in food matrices (Lass et al., 2012; Ahmad et al., 2016; Hohweyer et al., 2016).

\subsubsection{Global distribution}

The global prevalence of toxoplasmosis is estimated to be equivalent to $30 \%$ of the world population. However, the distribution of human exposure to the parasite varies from 0 to $100 \%$ (Jackson and Hutchison 1989; Chatterton 1992; Zuber and Jacquier 1995; Tenter et al., 2000; Dubey et al., 2012; Peyron et al., 2015). Seroprevalence varies among countries and regions within the same country due to individual subpopulations' religious practices, socioeconomic status, cultural habits, environmental factors (humid and warm climate), the presence of cats (Dabritz and Conrad, 2010), or other yet unknown factors that can have an impact on the epidemiology of toxoplasmosis. Anthropogenic factors can also influence the epidemiology of infection for humans (Tenter et al., 2000; Pappas et al., 2009; Afonso et al., 2010; RobertGangneux and Dardé, 2012). Seroprevalence in humans increases with age, but the rate of acquisition of infection in relation to age varies according to the country and socioeconomic level (Robert-Gangneux and Dardé, 2012). Between 11 and $40 \%$ of adults in the USA and UK have been found to be seropositive, but in other countries in western Europe, typical seroprevalence rates vary from 11 to $28 \%$ in Scandinavia, $25,7 \%$ in Portugal (Lito et al., 2013), $42 \%$ in Italy, and up to $67 \%$ in Belgium (Pappas et al., 2009). In Russia, $13.4 \%$ of children from 6 to 12 years of age were positive to T. gondii (Janse et al., 2014). In South America, in some regions of Brazil, infection rates of over $70 \%$ have been reported (Dubey et al., 2012). In Colombia seroprevalence was $47 \%$ in one national study in the general population and $63 \%$ in pregnant women (CañónFranco et al., 2014). Seroprevalences of approximately $40 \%$ have been reported from various African countries (RobertGangneux and Dardé, 2012). In New Guinea and Mozambique the seroprevalence was $53 \%$ in the general population (John et al., 2012) and 50.9\% in women of childbearing age (Domingos et al., 2013). High prevalence (40-60\%) was reported in North Africa and Middle East (MENA) countries including Morocco, Tunisia, Egypt, Lebanon, Jordan, Iraq, and Iran, whereas lower prevalences (20-40\%) were reported in Saudi Arabia, Bahrain and Qatar (Bouratbine and Aoun, 2014). In Asia, infection rates vary from less than $10 \%$ in some regions of China to $>60 \%$ in Mainao in the Philippines (Pappas et al., 2009; Zhou et al., 2011). A trend of decreasing seroprevalences has been observed in many European countries and the USA (Pappas et al., 2009), probably attributed, at least in part, to the hygienic improvements in animal husbandry. On the other hand, stable or increasing seroprevalences have been reported in Colombia, China, Brazil, and Korea (Adou-Bryn 
et al., 2004; Rosso et al., 2008; Zhou et al., 2011; Yang et al., 2012; Lim et al., 2012).

\subsubsection{Symptomatology}

Toxoplasma infection symptomatology and pathogenesis are variable and associated with the stage of infection and route of exposure. Symptoms typically differ between the initial acute stage, as compared with chronic, latent toxoplasmosis. The patient's immune status and age also influence the disease outcome (Holland, 2009). In immune competent adults during the acute stage, mild and nonspecific flu-like symptoms occur, such as fever, myalgia, enlarged lymph nodes, sore throat, and abdominal pain (Anand et al., 2012). Congenital toxoplasmosis occurs when the fetus becomes infected during pregnancy (Montoya and Liesenfeld, 2004). Congenital toxoplasmosis can produce mental retardation, hearing and ocular problems (Peyron et al., 2015). The most important medical consequences of fetal infection are hydrocephaly and retinochoroiditis (Figure 1), which can contribute to permanent neurological disabilities and severe visual impairment (McLeod et al., 2006; Olariu et al., 2011). In Colombia, a 25\% mortality rate due to vertically acquired toxoplasmosis has been described in newborns from untreated mothers (GómezMarin et al., 2011).

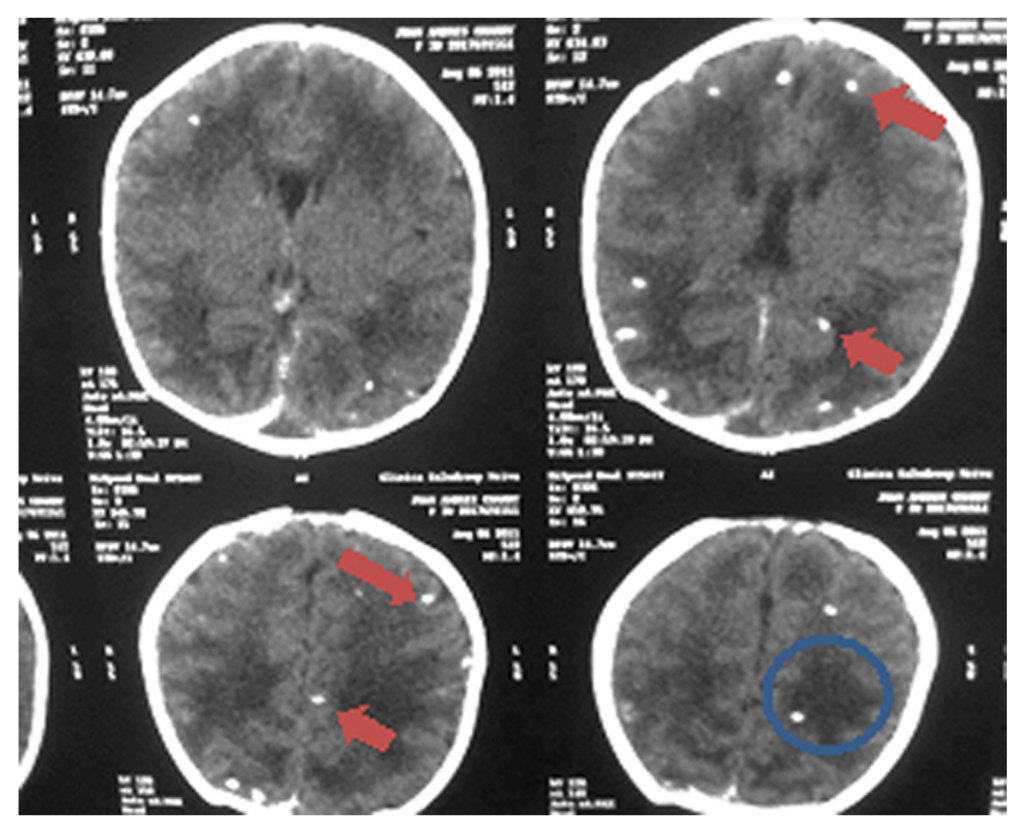

Figure 1. Cerebral tomography showing multiple cerebral calcifications (red arrows) and ventricular dilatation (bluecircle) in a children with congenital toxoplasmosis

Compared with Europe and North America, ocular toxoplasmosis (which can develop from congenital as well as from acquired infection), is more prevalent in South America, Central America, the Caribbean, and parts of tropical Africa, while it is quite rare in China (Kijlstra and Petersen, 2014; Petersen et al., 2012). Ocular toxoplasmosis is a significant cause of blindness (de-laTorre et al., 2009a), and the leading cause of posterior uveitis in the world (de-la-Torre et al., 2009b; BahiaOliveira et al., 2012; Holland, 2003). The pathology of ocular toxoplasmosis primarily affects the retina and choroids, where parasite lesions can be found (Figure 2). If lesions are located in the peripheral retina, manifestations may be asymptomatic; however, if macular lesions can lead to loss of central vision or complete loss of vision. Ocular toxoplasmosis was previously considered to occur only as a consequence of congenital infections, but it is now known that most cases result from acquired infection in immunocompetent individuals (Arantes et al., 2015; Jones et al., 2015). Why some people develop ocular manifestations and others do not is not completely established, but reasons likely include genetic host factors such as polymorphisms in cytokine genes or its promoters or cofactors (Peixoto-Rangel et al., 2009; Bahia-Oliveira et al., 2012; Dutra et al., 2013; Peixe et al., 2014; Kijlstra and Petersen 2014; Bahia-Oliveira et al., 2009). Differential virulence among parasite strains is also an important factor (de-la-Torre et al., 2013; Pfaff et al., 2014). In Colombia, Brazil, and the USA, it was estimated that ocular lesions will develop in approximately $10 \%$ of postnatally infected people (Kijlstra and Petersen, 2014; de-la-Torre et al., 2009b; Arantes et al., 2015). In Brazil, it was additionally determined that the risk of developing ocular toxoplasmosis after acquired postnatal infection was $6.4 \%$ per year (Arantes et al., 2015). 


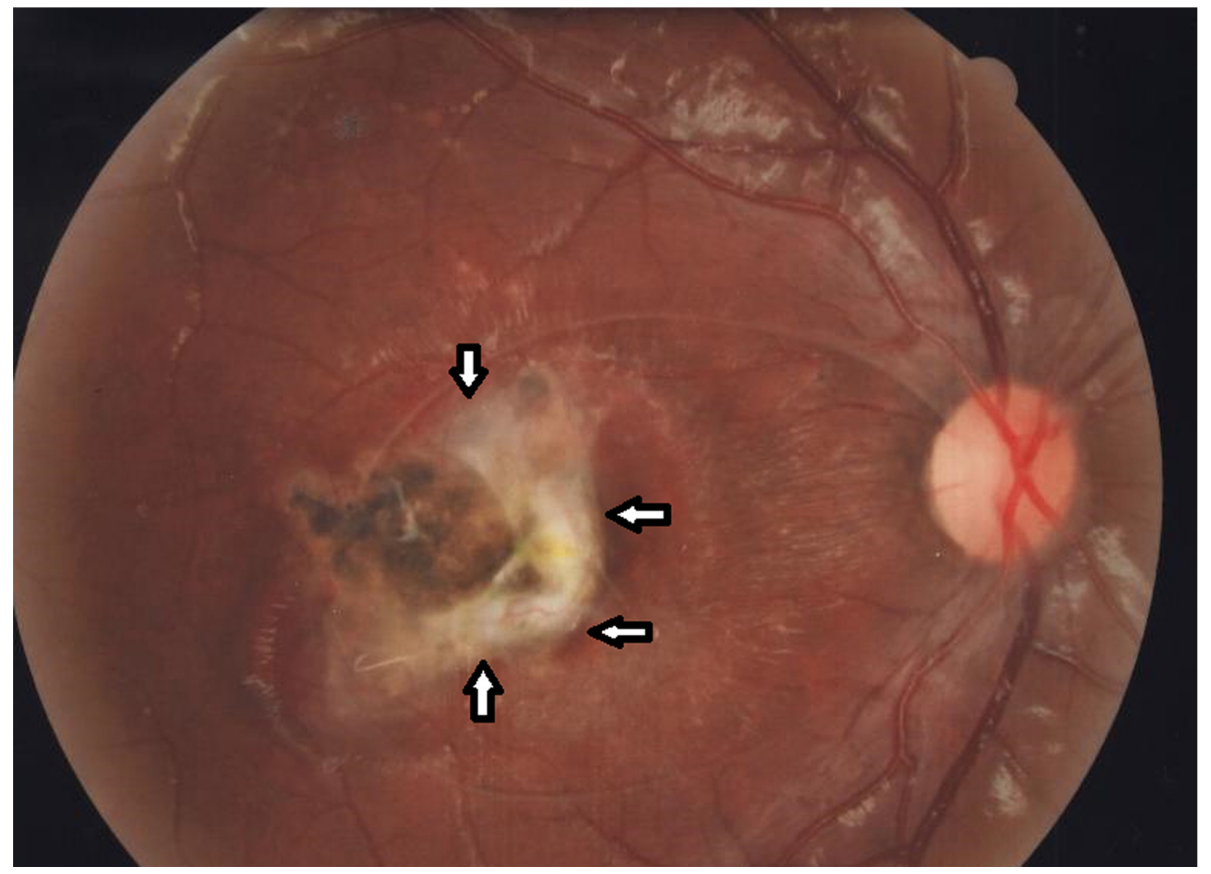

Figure 2. Retinochoroidal lesion in ocular toxoplasmosis (arrows)

Clinical signs and symptoms of cerebral toxoplasmosis can be focal or generalized, such as seizures, neuropsychological and cognitive disturbances, headache, focal cerebral signs (hemiparesis, hemianopia, ataxia, dysarthria), and impairment of consciousness (Maschke et al., 1999). Meningoencephalitis is the most important clinical presentation of toxoplasmosis in HIV-infected patients (Pereira-Chioccola et al., 2009) resulting from reactivation of past infection when CD4+ lymphocytes fall below $200 \mathrm{~mm}^{3}$ (Suzuki, 2002). In Europe and the USA, use of the highly active anti-retroviral therapy (HAART) has resulted in significant reduction of this clinical presentation. However in Africa and Latin America, it remains as the most important opportunistic disease in patients infected with HIV (Vidal et al., 2005). Cerebral or disseminated toxoplasmosis can also occur after transplantation of solid organs or hematopoietic stem cells. This risk depends largely on the prevalence of toxoplasmosis in the population and on the use of chemoprophylaxis after transplantation (Derouin et al., 2008; Martino et al., 2000). The incidence of toxoplasmosis after transplants varies from 9 to $56 \%$ depending on whether the patient receives chemoprophylaxis or not, respectively, indicating that prevention via antiprotozoal drugs can efficiently reduce the risk for transplant-borne infections (Derouin et al., 2008).

Numerous studies described association between higher prevalence of antibodies for T. gondii and mental disorders (Flegr and Hrdý, 1994;

Okusaga et al., 2011; Horacek et al., 2012). Epidemiological studies link toxoplasmosis with schizophrenia, some forms of depression, and higher rates of suicide and mood disorders (Okusaga et al., 2011; Pearce et al., 2012). A meta-analysis found that T. gondii seropositivity was 2.7 times higher in schizophrenic patients than in the general population (Torrey and Yolken, 2007). Although, there are epidemiological (Okusaga et al., 2011), laboratory (Elsheikha et al., 2016), and cerebral imaging studies (Horacek et al., 2012), these investigations have not convincingly linked cause and effect. Establishment of a definitive link between infection with $T$. gondii and mental disorders will require isolation and characterization of parasite strains from patients with psychiatric diseases and demonstration that treatment with anti-T. gondii pharmaceuticals is beneficial. In two doubleblind trials in chronic schizophrenic patients, there was no improvement of clinical condition by including anti- $T$. gondii medication (Dickerson et al., 2009; Shibre et al., 2010). However, one recent analysis of the outcome of bipolar patients exposed to T. gondii found more lifetime depressive episodes ( $p=0.048)$ after adjustment for age, sex and sociodemographic characteristics when treated by medication having no anti-T. gondii activity, compared to patients having received medication with anti-T. gondii effects (Fond et al., 2015).

\subsection{Taxonomic Classification of the Agent}

Toxoplasma gondii belongs to:

Phylum: Apicomplexa; Levine, 1970

Class: Sporozoasida; Leukart, 1879

Subclass: Coccidiasina; Leukart, 1879

Order: Eimeriorina; Leger, 1911

Family: Toxoplasmatidae, Biocca, 1956

Genus: Toxoplasma Nicolle and Manceaux, 1909 and there is only one species of Toxoplasma, T. gondii (Dubey, 
2010)

According to the new classification proposed by the International Society of Protozoology, this parasite is included in the supergroup SAR (Stramenopiles, Alveolata and Radicularia), first rank Alveolata and second rank Apicomplexa (Adl et al., 2012).

\subsubsection{Physical description of the agent}

There are three infective stages of $T$. gondii: the tachyzoites (rapidly dividing and invasive in groups or clones), the bradyzoites (slowly dividing in tissue cysts), and the environmental sporozoite stage (protected within the oocyst).

\subsubsection{Tachyzoite}

The tachyzoite (also called endodyozoite or endozoite) is characterized by rapid replication of this stage (in greek tachy $=$ rapid; zoite derived from zoo $=$ animal) $($ Frenkel, 1973) in any cell of the intermediate host and in nonintestinal epithelial cells of the definitive host (felines). Tachyzoites are crescent-shaped cells, approximately $5 \mu \mathrm{m}$ long and $2 \mu \mathrm{m}$ wide. After entering the host cell, the tachyzoite becomes ovoid and is surrounded by a parasitophorous vacuole (PV) where divisions will take place. The tachyzoite possesses a sharp apical end that is characteristic of other members of phylum Apicomplexa, and a rounded posterior end (Figure 3). Underlying a complex membrane (pellicle) that encloses the tachyzoite is closely associated cytoskeleton providing structural integrity and motility. Tachyzoites also possess a nucleus, centrioles, a mitochondrion, a Golgi complex, ribosomes, an endoplasmic reticulum, and a multiple-membrane-bound plastid-like organelle, the apicoplast (de Souza, 1972; de Souza and Souto-Padrón, 1978; Roos et al., 1999). In the apical end are polar apical rings and structures involved in cell invasion, including the conoid, rhoptries [ROPs], dense granules, and micronemes [MICs]), as depicted in Figure 3

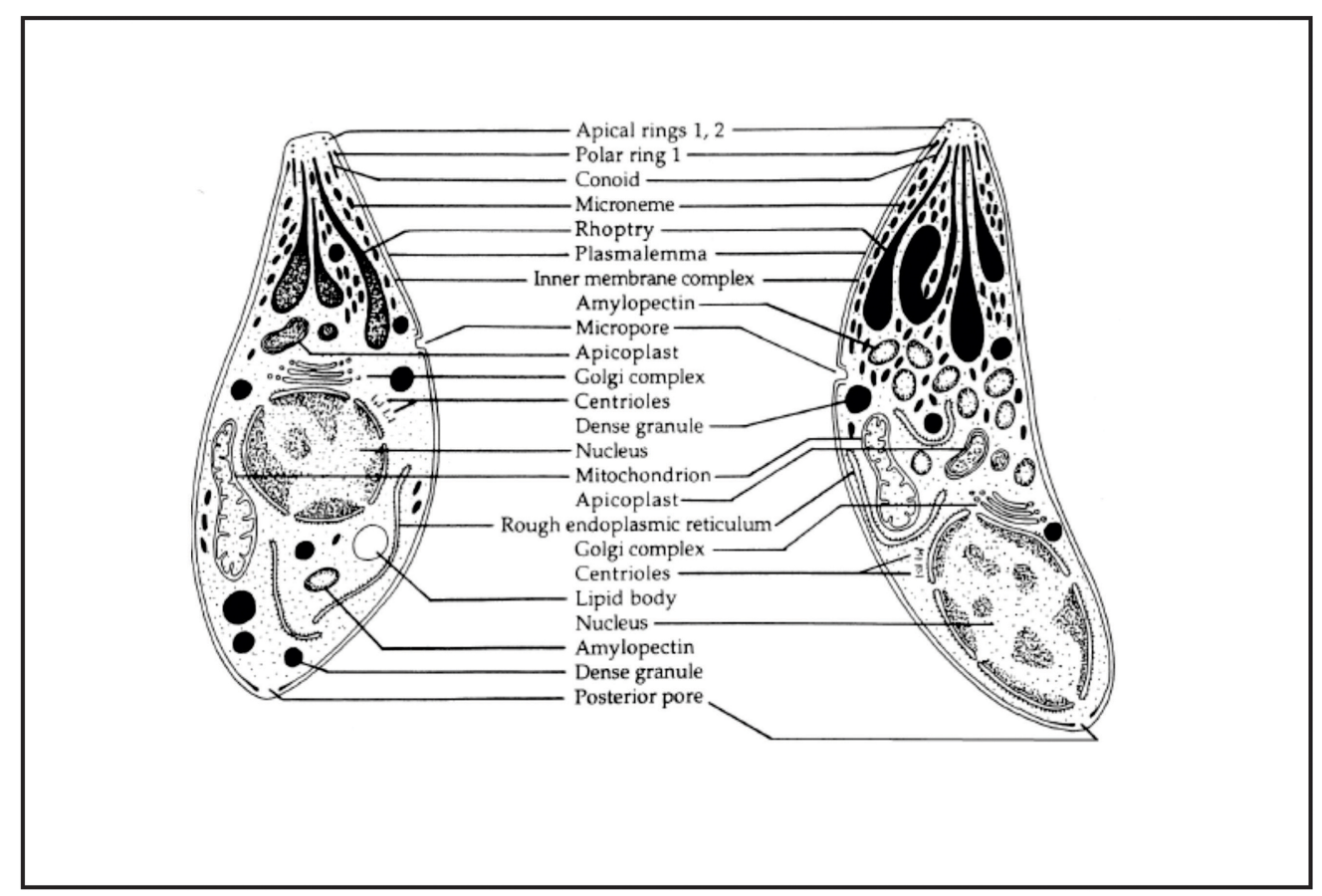

Figure 3. Schematic drawings of a tachyzoite (left) and a bradyzoite (right) of $\boldsymbol{T}$. gondii. The drawings are composites of electron micrographs Reproduced with permission from Dubey, J. P., Lindsay, D. S., \& Speer, C. A. (1998). Structures of Toxoplasma gondii tachyzoites, bradyzoites, and sporozoites and biology and development of tissue cysts. Clinical microbiology reviews, 11(2), 267-299

\subsubsection{Bradyzoite}

The bradyzoite (also called cystozoite) is characterized by slow replication (brady = slow in Greek) (Frenkel, 1973). They develop from the conversion of tachyzoites and form tissue cysts. They are structurally very similar to tachyzoites (Figure 3), but differ in metabolism, which is latent and adapted to long-term survival within host cells. Bradyzoites remain intracellular within tissue cysts, and slowly divide by endodyogeny (Ferguson and Hutchison, 1987a; Ferguson and Hutchison, 1987b). Tissue cysts can persist for the life of the host without causing a perceivable inflammatory response. They vary in size from small (young tissue cysts) cysts about $5 \mu \mathrm{m}$ in diameter (containing as few as two bradyzoites) to large $100 \mu \mathrm{m}$ tissue cysts (older and containing hundreds of bradyzoites). Large tissue cysts in the brain are spheroidal, whereas intramuscular cysts are elongated. The cyst wall is elastic, providing resistance of bradyzoites to acidic pepsin (1-2 hour survival in pepsin$\mathrm{HCl})$ facilitating survival through the stomach and infection in the intestine via carnivorism. 


\subsubsection{Oocysts and Sporozoites}

Sporozoites are the infective stage inside of mature (sporulated) oocysts that facilitate prolonged environmental survival of the parasite. The oocyst structure has an extremely robust multilayer composition (Mai et al., 2009), which protects the sporozoites from mechanical and chemical insults. Sporozoites within oocysts can survive for long periods, up to years, in favorable environments (section 2.3). Oocysts form from the sexual cycle that occurs only in the feline intestine. They are excreted in feline feces unsporulated (immature, i.e non-infective), subspherical to spherical with diameter of 10 by $12 \mu \mathrm{m}$.
Sporulation (formation of sporozoites) occurs only in the environment within 1 to 5 days of excretion depending upon aeration and temperature. Sporulated oocysts are subspherical to ellipsoidal, measure 11 by $13 \mu \mathrm{m}$ in diameter, and contain two sporocysts, each with four sporozoites (Dubey et al., 1998a) (Figure 4). Sporozoites are structurally similar to tachyzoites and bradyzoites, differing only in certain organelles and inclusion bodies (Dubey et al., 1998a).
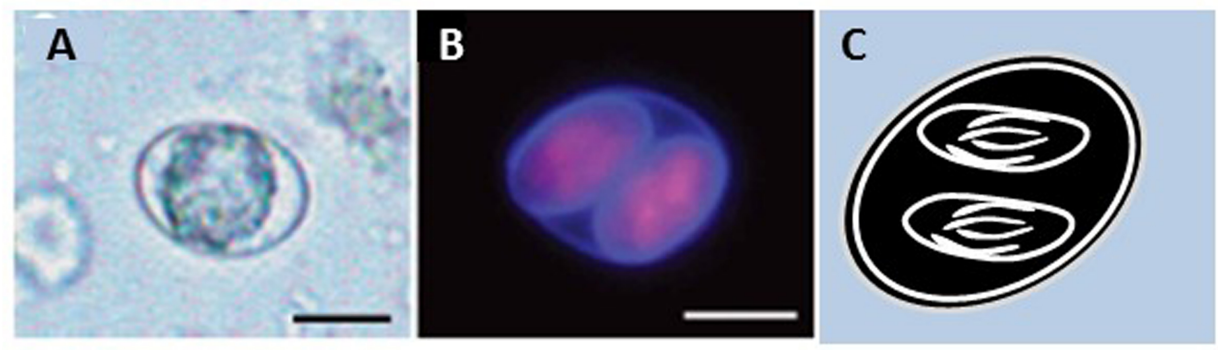

Figure 4. A- light micrography of an unsporulated oocyst showing a single cytoplasmic mass B-Fluorescent image of a sporulated oocyst with two sporocysts, it is not possible to visualize the four sporozoytes inside each sporocyst $C$ schematic drawing of a sporulated oocyst showing two sporocysts with four sporozoites each. Bar $=5$ pm. A and B reproduced from Ferguson, D. J. (2009). Toxoplasma gondii: 1908-2008, homage to Nicolle, Manceaux and Splendore. Memórias do Instituto Oswaldo Cruz, 104(2), 133-148.

\subsubsection{The complex parasite life cycle}

The three T. gondii life stages (oocyst/sporozoite, tachyzoite and bradyzoite) are connected in a complex life cycle represented in the diagram of Figure 5; for details and historical aspects of the parasite life cycle and structure see (Dubey et al., 1998a; Ferguson, 2009). T. gondii belongs to the tissue-cyst forming coccidian parasites, however, unlike enteric coccidian parasites, it utilizes an alternating two-host (heteroxenous), facultative life cycle (Ferguson, 2009; Dubey, 2010). In nature, the life cycle can be maintained by oocysts or bradyzoite-mediated infections, and therefore in theory the parasite can be maintained in the absence of the definitive host (felines) through carnivorism (Dubey et al., 1998a). Felines excrete oocysts in their feces after ingesting any of the three infectious stages of $T$. gondii. Once tissue cysts a re ingested, the cyst wall is dissolved by proteolytic enzymes in the stomach and small intestine of felids. The released bradyzoites penetrate the epithelial cells of the small intestine and develop numerous asexual generations of $\mathrm{T}$. gondii before gametogony begins. Gametogony depends on parasite differentiation that occurs during the asexual replications of the parasite in the feline intestines to produce male (micro) and female (macro) gametes within two days after tissue cysts were ingested by the felid. The oocyst is the developed zygote formed by fertilization of the macrogamete by the microgamete; it is released into the intestinal lumen and is excreted in feces. In the environment, oocysts sporulate (and become infective) within 1-5 days, depending on aeration, humidity and temperature. The asexual component of the life cycle occurs after intermediate hosts (including humans) ingest oocysts from contaminated water, unwashed fresh fruits and vegetables, raw seafood, or soil; or when ingesting uncooked or undercooked meat containing tissue cysts. After an acute infection with dissemination of tachyzoites throughout the body, tissue cysts form. 


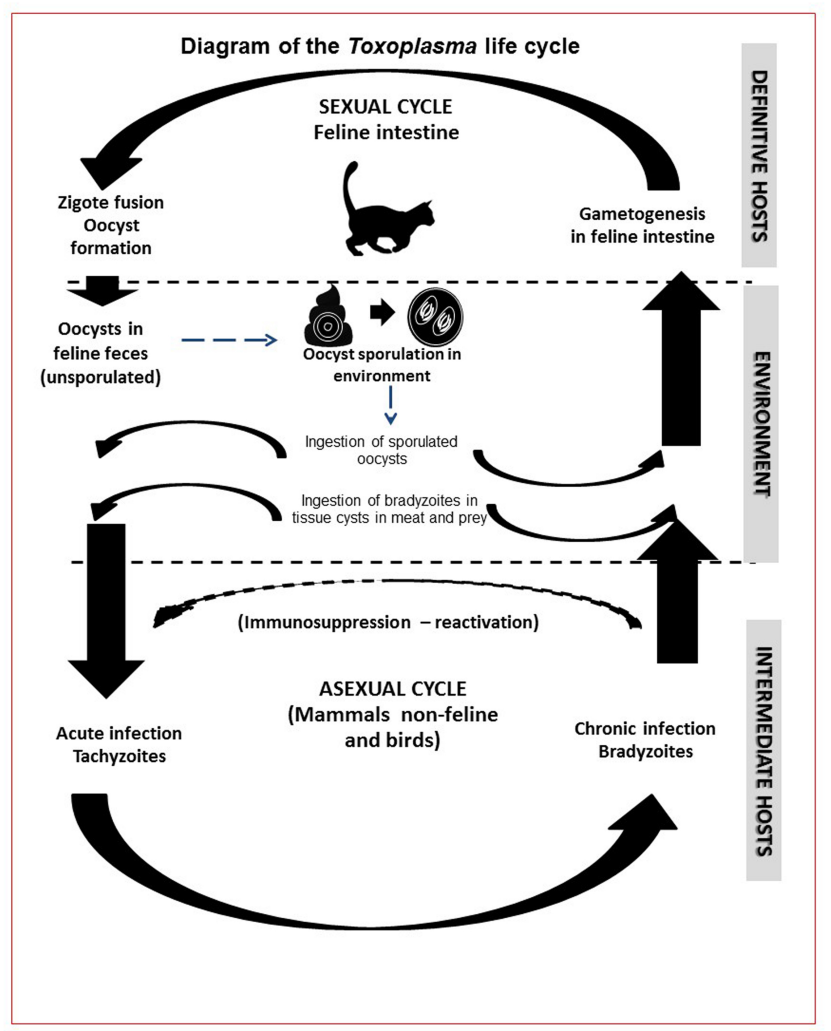

Figure 5 Life cycle of Toxoplasma gondii. The sexual cycle (top section-definitive host) is initiated when a domestic cat or a wild feline, ingest either oocysts through environmental transmission, or bradyzoite tissues cysts present in infected prey. Infected cats excrete oocysts that become highly infectious and survive in the environment for months to years. Any warm-blooded animal, including humans, that ingests oocysts (environmental transmission) becomes a host for the asexual cycle (bottom sectionintermediate hosts). Transmission to intermediate hosts also occurs upon ingestion of tissue cysts in uncooked or undercooked meat from a chronically infected animal. Modified from Michael W. Black, and John C. Boothroyd Microbiol. Mol. Biol. Rev. 2000;64:607-623 with permission. Graphic design by Bianca Magnelli Mangiavacchi (LBR-UENF) and Leonardo Gomes (UFRJ)

\subsubsection{Parasite population, strain diversity and virulence}

Toxoplasma has a haploid genome containing 14 chromosomes and 7.793 genes, with a total genome size of $63,495.144$ base pairs (Khan et al., 2007). Based on restriction fragment length polymorphism (RFLP), Howe and Sibley proposed $T$. gondii classification into three genetic types (I, II, III) based on strains isolated mainly in Europe and North America, and associated mouse virulence with genetic types. Type I isolates were $100 \%$ lethal to mice, irrespective of the dose, while types II and III in general were not virulent for mice (Howe and Sibley, 1995). A fourth clonal lineage was later reported and was largely confined to North America, where it is more common in wild animals (Khan et al., 2011). Since the conventional designation assumed the clonal population structure with Types I II and III, other genotypes have been identified worldwide and termed as "atypical" or "exotic" (Dardé et al., 2014). The largest multilocus and haplotype analysis in
950 strains found a biphasic pattern of global distribution of parasite population: highly clonal genotypes in the northern hemisphere and highly diverse unique haplotypes in South America. In total, 15 haplogroups were collectively defined as six major clades by using microsatellite and multilocus RFLP assays (Su et al., 2012). A greater genetic diversity of parasites was seen in South America vs. the predominant clonal structure seen in the Northern Hemisphere (Sibley and Ajioka, 2008). In South America the parasite populations are characterized by a diverse assemblage that show greater evidence of recombination (Su et al., 2012; Weiss and Kim, 2000). One hypothesis suggests that the parasite originated in South America, and that continental drift over hundreds of millions of years favored different evolution for different $T$. gondii strains (Lehmann et al., 2006).

Expansion and diversification of secretory pathogenicity determinants (SPDs) is a prominent feature of genomes of 
T. gondii and patterns of block inheritance may underlie specific traits shared by related lineages of $T$. gondii containing similar combinations of SPDs (Lorenzi et al., 2016). There exists evidence that several families of secretory proteins in $T$. gondii are important for preventing innate immunity and hence facilitating infection in the mouse (Hunter and Sibley, 2012). Moreover, specific virulent factors have been identified that correlate well with pathogenicity in mice and humans (Niedelman et al., 2012; Saeij et al., 2006; Alvarez et al., 2015; de-la-Torre et al., 2013; Sánchez et al., 2014). These virulent factors are predominantly kinase proteins that interact directly with host transcription factors modulating the immune response (Saeij et al., 2006). These virulent factors originate from rhoptry organelles (ROP proteins), with the most significant proteins described to date including ROP18, ROP16 and ROP5 (Niedelman et al., 2012; Ong et al., 2010). T. gondii genotypes analyzed in South American patients with severe clinical forms correlated with virulent genotypes of ROP proteins and modification of the cytokine immune response (Alvarez et al., 2015; Torres-Morales et al., 2014; de-la-Torre et al., 2013; de-la-Torre et al., 2014).

\subsubsection{Tissue Tropism/Cellular receptors/Latency}

\subsubsection{Tissue tropism}

Toxoplasma gondii sexual stages show restricted host tissue specificity for gut epithelial cells of feline species (Dubey, 2010). The asexual tachyzoite stage however, is able to invade virtually all warm-blooded cell types. In humans and animals, the distribution of T. gondii in tissues depends on the stage of the infection, and differs between the acute initial phase when parasites can be distributed in practically all organs, versus the latent chronic phase of the infection when distribution is limited to tissue cysts within nucleated cells, most frequently in brain, eye, skeletal muscle, and cardiac tissue. In the brain, cysts form in several regions, although a subtle tropism for the medial and basolateral amygdala has been reported (Vyas et al., 2007). In vivo studies demonstrated that, the parasite preferentially targets leukocytes (macrophage and dendritic lineage cells), for infection (Bierly et al., 2008; Chtanova et al., 2008; Courret et al., 2006), cells that have a central role in immunity, and are believed to serve as "Trojan horses", facilitating parasite dissemination and leading to establishment of latent infection in the central nervous system (CNS) and skeletal muscle after the initial acute phase of the infection. During this process, the parasite actively manipulates intracellular signaling networks of the immune system from within the infected cell (Butcher et al., 2014). Parasite tissue distribution is also determined by strain virulence, age, and immune status (Dubey, 1997; Dubey, 2006; Peyron et al., 2015). In congenital infections, the genesis of the natural infection in the fetus is similar to that observed in experimental toxoplasmosis in animals. The position of necrotic foci and lesions in general suggests that the organisms reach the brain and other organs through the bloodstream. In some cases, only the CNS and eyes may be involved, whereas in others, broad dissemination of lesions and parasites in several organs (including skin) may be observed. Between these two extremes exist wide variations in the degree of organ involvement, but the CNS is always involved, possibly because the CNS and eye, have the reduced ability of nerve cells to regenerate, resulting in more severe permanent damage (Peyron et al., 2015). In the latent stage of infection in intermediate hosts, a preferential parasite distribution has been observed in neural tissues (brain and eyes) and skeletal muscles (Dubey, 1997, Dubey, 2006).

\subsubsection{Cellular receptors}

Unlike viruses and intracellular bacteria, T. gondii actively penetrates host cells without using typical hostuptake pathways that involve parasite engulfment; nonetheless, parasite engulfment can occur under inflammatory circumstances. T. gondii has a limited capacity to survive outside a cell during infection. The broad specificity enabling $T$. gondii to invade all cell types suggests that the parasite has developed a means of using a widely expressed receptor, many different receptors, or perhaps a receptor produced by $T$. gondii itself. Initial cell penetration occurs within $15-20$ seconds and is complete within 1 to 2 minutes (Carruthers and Boothroyd, 2007). Many molecules are involved in the penetration process and more will undoubtedly be discovered. The apical pole directs cell invasion by means of exclusive deployment of transmembrane adhesins; the forward motion is also supported by unidirectional orientation of the actin microfilaments (Carruthers and Boothroyd, 2007). A multistep model that progressively increases the parasite's grip on the host surface has been proposed and depicts steps from initial attachment to host cell membranes to membrane separation inside the host cell (Carruthers and Boothroyd, 2007). The following molecular events involving parasite-host receptor recognitions have been described: A) an initial (reversible) attachment, via recognition of surface receptors by a group of parasite surface antigens termed SAGs (Nagel and Boothroyd, 1989; Boothroyd et al., 1998). The abundance and wide distribution of SAGs on the parasite surface optimally positions them for low-affinity interactions with the host surface cell membrane; B) apical attachment, which involves the calcium-dependent deployment of a group of micronemal proteins (MICs) (Carruthers et al., 1999; Cérède et al., 2005) and their accumulation on the apical surface; $\mathrm{C}$ ). The release of rhoptry neck (RON) proteins which associate with microneme-derived apical membrane antigen (AMA1) and form the moving junction (located in plasma membranes where the host and parasite are in intimate contact) (Besteiro et al., 2009); and D) simultaneously or immediately thereafter, rhoptry proteins (ROPs) are injected (discharged) into the host cytoplasm at the invasion site (Boothroyd and Dubremetz, 2008; Carruthers et al., 1999; Carruthers and Boothroyd, 2007). Some ROPs remain associated with small vesicles that fuse with the developing parasitophorous vacuole membrane (PVM) (Håkansson et al., 2001) during penetration, whereas other ROPs remain soluble and target other sites within the host cell that play an important role in establishing infection (Butcher et al., 2014). 


\subsubsection{Latent infections}

Bradyzoites in tissue cysts represent the hallmark of latent toxoplasmosis, a chronic, life-long infection that is refractory to pharmacological or immune elimination. Tissue cysts have been found at autopsy from patients who died of unrelated causes and in organs removed surgically (Remington and Cavanaugh, 1965; Pusch et al., 2009). They remain infectious in skeletal, heart and neural tissues, enabling the parasite to spread to a new host following predation and carnivorism (Sullivan and Jeffers, 2012). The ability of bradyzoites to reconvert into rapidly replicating tachyzoites explains the high frequencies of acute toxoplasmosis often observed in immunocompromised individuals (Montoya and Liesenfeld, 2004; Wong and Remington, 1993; Pereira-Chioccola et al., 2009). Mature tissue cysts can be detected after 7-10 days post-infection. No short or long-term treatment has proven successful in eliminating tissue cysts. This aspect differs from common pharmaceutical approaches that are available to control acute toxoplasmosis that target the rapidly replicating tachyzoite stage that causes clinical illness such as congenital, ocular and cerebral toxoplasmosis.

\subsection{Transmission}

\subsubsection{Routes of transmission}

Toxoplasma can be transmitted by oral and non-oral routes. For oral infection, the epidemiologic importance of whether toxoplasmosis is transmitted by oocysts or tissue cysts has been debated even before the life cycle was determined in the 1970's (Jackson and Hutchison, 1989). Because vegetarians and non-vegetarians had similar prevalence rates (Jacobs, 1957, Rawal, 1959), carnivorism could not be the only source of infection. The association between toxoplasmosis and rainfall (Tizard et al., 1976; Sagel et al., 2010; Gómez-Marin et al., 2011; Schares et al., 2016) indicated the importance of water in the transmission of $T$. gondii. Oocysts can be found in contaminated water, on unwashed fresh fruits and vegetables, raw seafood, or in soil (section 2.2). Bradyzoites are transmitted when ingesting uncooked or undercooked meat containing tissue cysts. Figure 6 depicts the main routes for $T$. gondii transmission, considering an initial common source of parasite contamination via water and or soil. The "Toxoplasma gondii tree" illustrates the two common "roots" - water and/or soil - which form the base matrices for disease transmission through subsequent routes, including non-oral routes of human-to-human infections via congenital transmission, organ transplantation, and/or blood transfusion. This tree also illustrates the importance of environmental contamination by infective (sporulated) T. gondii oocysts through different matrices, including sewage water and sludge (treated or not), in both "trees".

Conventional serological commercial tests recognize antigens from tachyzoites but cannot determine the predominant route (oocysts or tissue cysts) of transmission. Evaluating the relative epidemiologic importance of oocyst versus tissue cyst transmission has recently become feasible in serological tests (Munoz-Zanzi et al., 2010; Hill et al., 2011; Boyer et al., 2011; Vieira et al., 2015; Santana et al., 2015) and saliva (Mangiavacchi et al., 2016) of patients by means of an ELISA using recombinant antigens: the sporozoite-specific embryogenesis-related protein (TgERP) (Hill et al., 2011), and the CCp5A recombinant protein (Santana et al., 2015). Discriminating the route of infection represents an essential step for implementing effective prevention measures for reducing exposure to the parasite in more vulnerable groups, such as pregnant woman and immunocompromised patients. In the USA, the ingestion of infective oocysts is responsible for a majority of human infections (Jones et al., 2014). Unrecognized ingestion of $T$. gondii oocysts leading to congenital toxoplasmosis and causing disease outbreaks has been reported (Boyer et al., 2011). Oocysts were the predominant source of $T$. gondii infection in four North American outbreaks, and in mothers of children in the National Collaborative Chicago-based Congenital Toxoplasmosis Study (NCCCTS). This latter study showed that 59 (78\%) of 76 mothers of congenitally infected infants had primary infection due to oocysts, and more importantly, that from the 76 infected mothers only 49\% (37 mothers) identified significant risk factors for sporozoite acquisition (Boyer et al., 2011). In an endemic setting in Brazil, where exposure to water contaminated with $T$. gondii oocysts has been reported to be a significant risk factor (Bahia-Oliveira et al., 2003), more than $50 \%$ of the population (older than 20 years) infected with $T$. gondii had antibodies against sporozoites (Vieira et al., 2015); and in persons younger than 20 years, more than $65 \%$ had IgA against sporozoite antigens in saliva (Mangiavacchi et al., 2016) - indicating recurrent exposure to infective oocysts. In women who acquired $T$. gondii during pregnancy in Chile, $43 \%$ had oocyst-specific antibodies (Munoz-Zanzi et al., 2010). These studies illustrate that establishing effective prevention measures necessitates the investigation of sources of infection to specific populations on a region-by-region basis.

\subsubsection{Transmission by oral routes - oocysts}

Oocysts in feline feces can persist in water and soil for long periods and can be ingested by humans in untreated or inadequately treated water and through recreational activities in surface waters (fresh or marine). Oocysts can also be ingested from contaminated vegetables and fruits, through paratenic hosts such as shellfish, and accidentally from water or soil (Frenkel and Ruiz 1981; Jones et al., 2009; Jones and Dubey, 2010; Jones et al., 2014; Karanis et al., 2013; Meireles et al., 2015). The confirmed presence of oocysts in contaminated matrices implicated in infections (water, shellfish, soil, vegetables and fruits) has been scarce because of limitations of currently available detection methods (section 2.1). The likelihood of T. gondii detection is greater during outbreak situations, such as the large waterborne outbreak that occurred in Brazil (de Moura et al., 2006).

\subsubsection{Transmission by oral routes - tissue cysts}

Toxoplasmosis has been largely known as a disease 
transmitted by ingestion of cysts in raw and undercooked meat containing the bradyzoite stage (Weinman and Chandler, 1954; Desmonts et al., 1965; Jackson and Hutchison, 1989; Dubey, 2010). The decrease of T. gondii prevalence in the USA (Jones et al., 2007) and Netherlands (Hofhuis et al., 2011) has been attributed at least in part to hygienic improvements in animal husbandry. Measures for reduction of environmental contamination with $T$. gondii oocysts are critically important to insure farming practices that offer improved animal welfare while protecting food animals from exposure to the parasite (Kijlstra and Jongert, 2009).

\subsubsection{Transmission by oral routes - tachyzoites}

Tachyzoites transmitted orally by ingestion of raw milk or other dairy products has been reported (Boughattas, 2015a; Boughattas, 2015b; Capobiango et al., 2015). Risk assessment studies associating T. gondii infections and milk consumption have showed wide divergence of results (Boughattas, 2015b), but the increase in demand for unpasteurized milk has raised concerns that consumers may be exposed via this route. Further investigations and consumer awareness should be undertaken with respect to the safety of unpasteurized vs. heat-treated milk (Boughattas, 2015b). Raw eggs may also be considered a potential source for T. gondii infection. Experimentally induced infection in hens resulted in isolation of $T$. gondii from raw eggs (Jacobs and Melton, 1966). However, eggs from commercially raised poultry were shown to be virtually free of $T$. gondii infection, and tachyzoites are highly susceptible to both heating and salt concentration; therefore, any type of cooking would kill tachyzoites in eggs (Tenter et al., 2000).

\subsubsection{Transmission by non-oral routes}

\subsection{Congenital toxoplasmosis}

Congenital toxoplasmosis infection is acquired via transplacental route (human-to-human transmission). It is generally believed that protective immunity in response to T. gondii infection in mothers exposed prior to pregnancy can usually prevent vertical transmission to the fetus. However, when T. gondii infection is acquired for the first time during pregnancy, or with lower probability shortly before conception, the parasite can be transmitted to the fetus if tachyzoites cross the hemato-placental barrier (Peyron et al., 2015). The risk of congenital transmission varies with the gestational age and whether the mother receives treatment or not (Cortina-Borja et al., 2010; Hotop et al., 2012; Kieffer et al., 2008; Wallon et al., 2013; Prusa et al., 2015). The overall risk of toxoplasmosis transmission, in mothers who have been treated during gestation, is approximately 30\% (Bessières et al., 2001; Thiébaut et al., 2007). In rare cases $T$. gondii has been transmitted to offspring of immunocompetent mothers who were confirmed to be $T$. gondii immune before pregnancy (Gavinet et al., 1997; Ladas et al., 1999; Kodjikian et al., 2004; Elbez-Rubinstein et al., 2009; Valdès et al., 2011; Franco et al., 2015). In one case, ingestion of imported raw horse meat during pregnancy was the source of the mother's re-infection. The isolated strain from the newborn's blood suggested that the mother's acquired immunity against a European strain did not protect against vertical transmission when the mother was infected by the strain in the imported meat (Elbez-Rubinstein et al., 2009). Furthermore, congenital transmission cases have been reported in previously infected women with systemic lupus erythematosus (SLE) (Wechsler et al., 1986) or acquired immunodeficiency syndrome (AIDS) (Campos et al., 2014).

\subsection{Other non-oral routes of transmission}

Solid-organ transplantation, hematopoietic stem cell transplants, blood transfusion, and laboratory accidents provide further means of $T$. gondii transmission by tachyzoite/bradyzoite stages. In solid-organ transplantations, transmission occurs from a T. gondii seropositive donor to a $T$. gondii -seronegative recipient. This risk is highest for heart transplants, and is significantly lower for other solid organs. In hematopoietic stem cell transplants, complications are related to the reactivation of a preexisting latent infection due to suppressive therapies (Derouin et al., 2008). Blood transfusion is thought to be a rare source of transmission because the duration of parasitemia during acute infection is brief; however, parasites have been detected in human blood during the chronic phase of infection (Miller et al., 1969). A systematic review and meta-analysis report of blood donors reported the overall weighted prevalence of exposure to T. gondii in blood donors as 33\% (95\% CI, $28 \%-39 \%)$. The highest and the lowest seroprevalences of T. gondii exposure in donors were observed in Africa (46\%; 95\% CI, 14\%-78\%) and in Asia (29\%; 95\% CI, 23\%-35\%), respectively. Brazil (75\%) and Ethiopia (73\%) have been additionally identified as countries with high seroprevalence among blood donors (Foroutan-Rad et al., 2016). In addition, tachyzoites have been reported to be transmitted by accidental injection in the laboratory (Herwaldt, 2001).

Tachyzoites have been detected in tears, saliva, sputum, urine, and semen, but there is no evidence of horizontally transmitted toxoplasmosis (reviewed in (Tenter et al., 2000). 


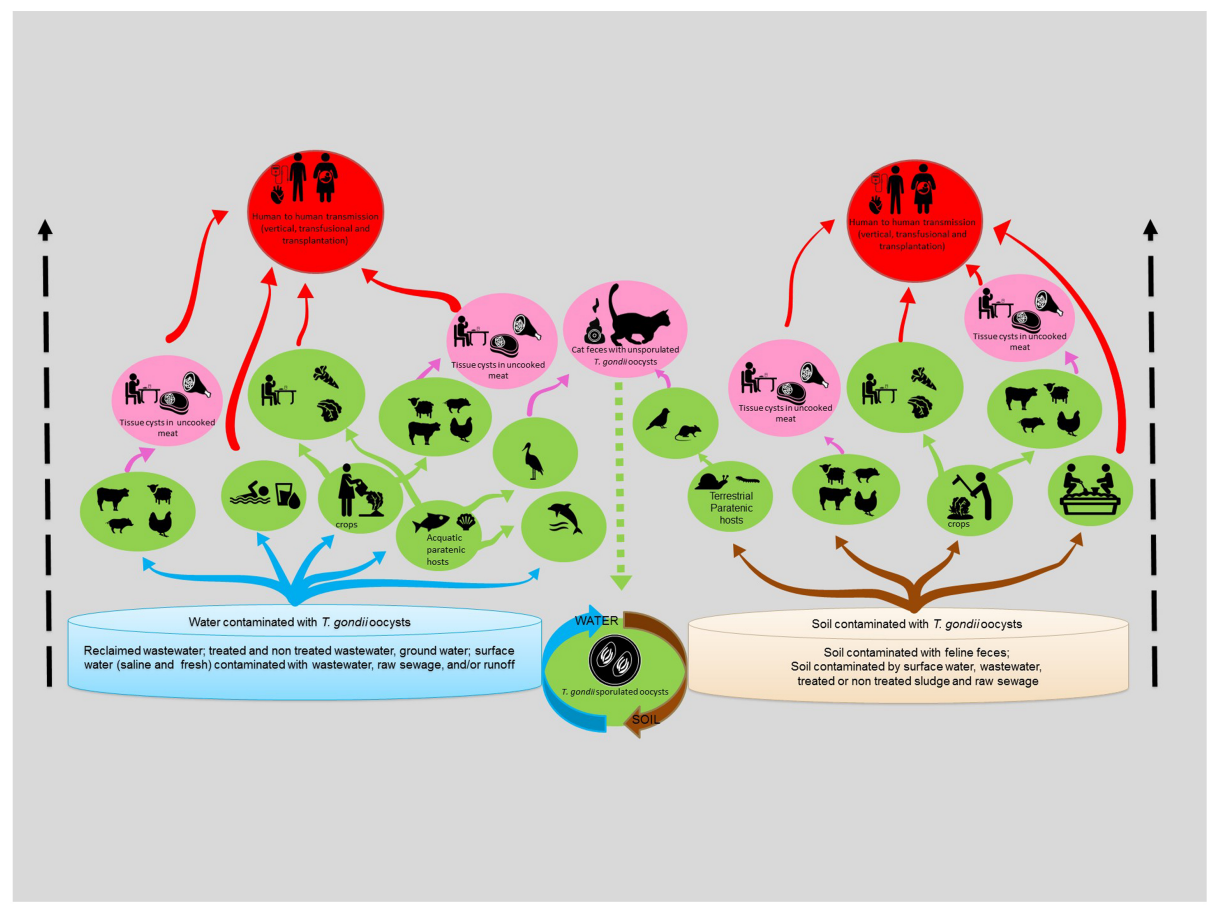

Figure 6. "Toxoplasma gondii tree" transmission. The flux of environmental transport and infection with T. gondii starts with oocysts shed in cat feces that contaminate soil and/or water. T. gondii oocysts are subsequently transmitted to hosts (intermediate, paratenic and definitive). Green ovals represent different sources/scenarios of contamination/infections caused by ingestion of oocysts; pink ovals represent scenarios of transmission via bradyzoites (tissue cysts); and red ovals represent human-to-human transmission caused by vertical (congenital), transfusional, or organ transplantation infections. Water is represented in blue with blue arrows depicting infection or contamination transmitted directly from water sources to hosts. Soil is represented in brown with brown arrows depicting infection or contamination transmitted directly from sources of soil to hosts. In both trees: green arrows depict infections transmitted by oocyst ingestion from different sources. Pink arrows represent infections transmitted by tissue cyst (containing bradyzoites) ingestion. Red arrows represent human-to-human transmission that is caused by tachyzoites by transplacental passage (vertical infection) and tachyzoites or bradyzoites (converting to tachyzoites). This figure does not depict the potential route of cat infection via oocysts or tachyzoites because these stages are less probable source of infection to cats and would produce infections with lower probability of oocyst shedding by cats (section 1.3.3). Graphic design by Bianca Magnelli Mangiavacchi (LBR-UENF) and Leonardo Gomes (UFRJ)

\subsubsection{Reservoirs}

Animals and environmental matrices can harbor $T$. gondii, and serve as potential sources (reservoirs) of disease transmission (see figure 6). However felids, specifically the domestic cat, have a central role as the source of infective oocysts. The implications of increasing cat populations as a public health risk due to toxoplasmosis was reviewed (Dabritz and Conrad, 2010). Important changes occurred in the USA that significantly increased the cat population: 1) pet cat ownership grew from 50 million to 90 million animals during the 1980s and 90s; and 2) animal welfare activists created feeding stations for abandoned and free-roaming cats. One consequence has been increased T. gondii oocyst entry to the environment, associated with higher risk of transmission to humans and animals. The authors recommend that preventive efforts that educate cat owners about the importance of collecting cat feces in litter boxes, reducing the numbers of feral cats, and promoting rigorous hand hygiene after gardening or contact with soil (Dabritz and Conrad, 2010). One route of largely overlooked environmental transmission has been ingestion of paratenic hosts contaminated with oocysts (Fig $6)$. These invertebrates are able to concentrate oocysts in their tissues - without parasite replication - and thereby act as reservoirs of oocysts for intermediate hosts that ingest these invertebrates as prey (or food to humans). This transmission route is believed to play a central role in $T$. gondii transmission in species such as California sea otters. In sea otters, small marine snails have been epidemiologically linked as a risk factor for exposure to $T$. gondii (Johnson et al., 2009), and these snails have been shown to act as effective paratenic hosts for the parasite (Krusor et al., 2015). Other marine invertebrates including mussels and oysters have been shown to harbor infective $T$. gondii oocysts for up to 85 days (Arkush et al., 2003; Lindsay et al., 2004), and could transmit the parasite not only to marine animals but also to humans who consume raw or undercooked shellfish (Jones et al., 2009). Additional invertebrates that have been determined to act as paretenic hosts in the terrestrial environment include earthworms, isopods and flies (Frenkel et al., 1975), as well as cockroaches (Wallace, 1973). In some cases, intermediate hosts can dually serve as mechanical hosts that can transmit oocysts: this has been shown in dogs where presence of $T$. gondii oocysts in feces has been detected, presumably due to coprophagy (Lindsay et al., 1997). 


\subsubsection{Incubation period}

The incubation time varies for the cat (definitive) and humans (intermediate) hosts depending on the T. gondii life stage initiating infection. In felids, the time between excretion of oocysts and the initial infection (called the prepatent period) varies according to the stage of T. gondii ingested (Dubey, 2006; Dubey, 1996; Dubey and Frenkel, 1976; Freyre et al., 1989). Prepatent periods are 3 to 10 days after ingesting tissue cysts, more than 18 days after ingesting oocysts (Dubey, 1996), and 13 days after ingesting tachyzoites (Dubey, 1998a). Only 30\% or less of cats excrete oocysts in their feces after ingesting tachyzoites or oocysts, whereas nearly all cats that ingest tissue cysts excrete oocysts (Dubey and Frenkel, 1976; Dubey, 1996). Bradyzoites in tissue cysts are also present in extra-intestinal tissues of cats, similar to intermediate hosts (Dubey, 1996). Intermediate hosts do not excrete oocysts, however, their incubation periods from the time of exposure until they present symptoms and a detectable immune response vary depending on the parasite stage initiating the infection. Data from human outbreaks estimate incubation periods of 10 to 23 days after ingesting bradyzoites in tissue cysts, and 5 to 20 days after ingestion of oocysts. Ingestion of tachyzoites can produce longer incubation periods in humans - similar to the ingestion of bradyzoites in tissue cysts (Meireles et al., 2015).

\subsubsection{Period of communicability}

Humans do not serve in general as a source of transmission and are not considered contagious. Notification is not required for toxoplasmosis.

\subsubsection{Population susceptibility}

Although one third of the world population is estimated to be infected with $T$. gondii, the sources of infection can vary locally according to environmental and social characteristics, including eating habits, the presence of felids, water sources, and agricultural practices. It is therefore critical that all of these aspects be studied locally, so effective prevention measures can be successfully implemented for specific regions and/or populations. In this context it is also important to consider the possibility of acute primary toxoplasmosis in travelers returning from endemic countries (Anand et al., 2012). Variation in $T$. gondii exposure can also be explained by a "household effect" within the context of parasite transmission (Fromont et al., 2009). For example, T. gondii prevalence can vary between 6 and $91 \%$ (5th and 95th percentile of the household seropositivity distribution), and be associated with common exposure routes of household members at a local scale - relative to local risk factors such as the presence of oocysts in soil (Fromont et al., 2009).

For estimates of human toxoplasmosis in different geographical regions of the world (Hald et al., 2016), three groups of risk factors appeared to account for the majority of cases: waterborne, soil contact, and foodborne. Significant variation occurs among geographical regions, but significant trends demonstrate a greater importance for soil and waterborne infections in developing world regions compared with northern hemisphere locations (Hald et al., 2016). Epidemiological investigations have further demonstrated an association of toxoplasmosis with seasonal cycles (Tizard et al., 1976). Global climatic factors such as moisture, temperature, and rainfall can affect the parasite's transmission by influencing parasite survival and distribution of oocysts (section 2.2.1) (Bowie et al.,1997; Fromont et al., 2009; Sagel et al., 2010; GómezMarin et al., 2011; Schares et al., 2016).

\subsection{Population and individual control measures}

Education regarding the risk factors for exposure to $T$. gondii is important for preventing infections at population and individual levels. Thus, a fundamental question for public health policy adoption is the identification of risk factor(s) that should be addressed for optimizing prevention programs, and how their relative importance (based on proportion of infections due to this factor) in a given location should be measured. Several studies have demonstrated that education programs should focus on the required achievements, in terms of behaviors and healthy lifestyle, rather than on a perfect knowledge pertinent to specific pathogens (Jones et al., 2003; Ogunmodede et al., 2005; Pereboom et al., 2013). One metanalysis of randomized trials that estimated the effect of prenatal education on congenital toxoplasmosis rates (or T. gondii seroconversion rates during pregnancy) indicated a need to focus on diverse strategies of education (Di Mario et al., 2015).

\subsubsection{Vaccines}

Many efforts have been made to develop vaccines against $T$. gondii to reduce oocyst shedding in cats and tissue cyst formation in mammals over the past 20 years (Zhang et al., 2013). Promising results have been reported using intranasal immunization of cats with rhoptry antigens, which reduced the quantity of oocysts shed in feces (Zulpo et al., 2012). A relatively successful vaccine is currently licensed for use in sheep to reduce abortions, and is based on an attenuated strain (Buxton and Innes, 1995). However, vaccine candidates have not been tested in humans, consequently there are no vaccines to protect against human toxoplasmosis.

Several reviews are available in the scientific literature regarding many strategies of vaccine development for toxoplasmosis (Vargas-Villavicencio et al., 2016; Kur et al., 2009; Jongert et al., 2009; Pfaff and Candolfi 2008). Vaccine candidates have been evaluated in vitro for immunogenicity and in vivo with challenges in murine and monkey models of infection and for diverse strategies of vaccine design, such as attenuated parasites, recombinant proteins from surface antigens, peptides and DNA (VargasVillavicencio et al., 2016; Kur et al., 2009; Pfaff and Candolfi 2008; Jongert et al., 2009). The most advanced candidate for a human vaccine, a peptides cocktail with adjuvant (Cong et al., 2012), has been evaluated ex-vivo in human T cells (Henriquez et al., 2010). It is limited by the 
need to include peptides that could be recognized for as many human haplotypes as possible to cover most of the human population (Cong et al., 2012). Recent advances in immunoinformatics have afforded a new rational strategy to select highly immunogenic peptides for humans, (Cardona et al., 2015).

\subsubsection{Individual control measures}

There are certain universal measures to help individuals prevent T. gondii infection, particularly for high-risk groups such as pregnant woman and immunocompromised individuals (Hughes et al., 2000). For meat: The US Department of Agriculture recommends cooking whole cuts of pork, lamb, veal, or beef to $62.8^{\circ} \mathrm{C}$ or higher as measured with a food thermometer placed in the thickest part of the meat, with a 3-minute rest time after cooking, but it is best to cook whole cuts of pork, lamb, veal, or beef to a least $65.6^{\circ} \mathrm{C}$ with a 3-minute rest, ground meat and wild game meat to $71.1^{\circ} \mathrm{C}$, and poultry to $73.9^{\circ} \mathrm{C}$ (Jones and Dubey, 2012). Microwave cooking is unreliable for killing T. gondii (Jones and Dubey, 2012). Freezing meat to an internal temperature of $-12^{\circ} \mathrm{C}$ kills T. gondii tissue cysts (Dubey, 2009; Jones and Dubey, 2012). It is also important to prevent cross contamination from raw meat to other foods, to wash hands thoroughly after handling raw meats. Cutting boards, dishes, counter tops, and utensils should be washed with soapy water after contact with raw meat (Peyron et al., 2015). For water: In Brazil and Colombia, drinking unboiled water increases the risk of $T$. gondii infection and drinking spring-bottled water reduces the risk of infection (Dattoli et al., 2011; de Moura et al., 2006; Bahia-Oliveira et al., 2003; López-Castillo et al., 2005). Chlorine treated water can still harbor T. gondii oocysts, a problem that may be less prevalent in northern hemisphere regions as compared with tropical countries (Trivino-Valencia et al., 2016; Karanis et al., 2013; Mahmoudi et al., 2015; Yang et al., 2009).

Individual measures to reduce $T$. gondii exposure from water, soil, and seafood to help prevent toxoplasmosis are listed below.

- Cover children's sandboxes when your children aren't playing in it to keep cats from using it as a litter box

- Change the litter box of pet cats daily so that excreted oocysts don't have time to become infectious. Pregnant women and immunocompromised individuals should avoid changing cat litter; if no one else is available to change the cat litter, use face masks and gloves followed by thorough hand-washing with soap and adequately treated water

- Pregnant women and immunocompromised individuals should use gloves when gardening, followed by thorough hand-washing with soap and adequately treated water

- Untreated or inadequately treated drinking water, as well as ingestion of raw food products made with untreated or inadequately treated water (including ice-cream), can cause $T$. gondii infection in immunocompetent persons mainly in developing countries. Thus, pregnant women and immunocompromised individuals residing in, or travelling to, regions with endemic $T$. gondii contamination, should only drink filtered, boiled or spring water, and eat products made with adequately treated water.

- Seafood, including shellfish, should be thoroughly cooked to kill T. gondii oocysts.

- Pregnant women and immunocompromised individuals should not recreate in surface waters with known or suspected sources of fecal contamination; and while recreating - be careful to avoid ingesting water.

- Thoroughly wash fruits and vegetables with adequately treated water before eating, even before peeling fruit.

- Clean cooking surfaces and utensils after they have contacted seafood, or unwashed fruits or vegetables.

Individual measures to prevent $T$. gondii infection from food animal (warm-blooded) sources include:

- Avoid eating raw or undercooked meat of any animal - especially lamb, goat and pork. Don't taste meat before it is fully cooked. Avoid raw cured meat.

- Cook meat thoroughly (i.e., at sufficient temperature to kill T. gondii bradyzoite cysts).

- Clean cooking surfaces and utensils after they have contacted raw meat and poultry.

- Wash hands thoroughly after handling raw meats.

- Avoid drinking unpasteurized milk and/or eat dairy products made with unpasteurized milk since they may contain T. gondii tachyzoites.

Collective measures to prevent $T$. gondii exposure include:

- Do not feed raw or undercooked meat to cats and keep cats indoors to prevent acquisition of T. gondii by eating infected prey.

- Prevent environmental contamination with viscera of hunted animals by burial to prevent scavenging by animals, especially cats.

Public policy for meat and agricultural industries (including organic production) to prevent $T$. gondii exposure include:

- Promoting education for women of childbearing age and immunocompromised persons with information about preventing $T$. gondii transmission including food hygiene and avoiding exposure to contaminated environmental sources.

- The meat industry should continue employing good production practices to reduce the presence of $T$. gondii in meat such as keeping cats and rodents out of food animal production areas and using clean or adequately treated water sources for the animals.

- The agricultural industry should employ good production practices to reduce oocyst contamination of crops.

- The government should encourage, help and 
support research on methods to reduce contamination of the environment with $T$. gondii oocysts and cysts in meat.

\subsubsection{Drug Therapy}

The treatment of choice for all clinical forms of human toxoplasmosis is the combination of pyrimethamine plus sulfadiazine (McLeod et al., 2009; McLeod et al., 2006; dela-Torre et al., 2011; Pereira-Chioccola et al., 2009; Wilson et al., 2010; Peyron et al., 2015). Folinic acid is added to prevent the hematopoietic toxicity of pyrimethamine. For congenital infection, the recommended duration is one year (McLeod et al., 2006). In ocular toxoplasmosis, classic therapy consists of pyrimethamine and sulfadiazine plus corticosteroids. Good response with resolution of inflammation and apparition of the characteristic hyperpigmentation of lesion can be observed after 4-6 weeks of treatment (de-la-Torre et al., 2011). An alternative antibiotic therapy for ocular infection or cerebral toxoplasmosis is the combination of trimethoprim (80 $\mathrm{mg}) /$ sulfamethoxazole (400 mg) every $12 \mathrm{~h}$ during 6 weeks (dela-Torre et al., 2011; Vidal et al., 2005). In countries where sulfadiazine is not available, the use of a combination of pyrimethamine with sulfadoxine is an alternative (GomezMarín et al., 2001).

\subsection{Environmental Occurrence, Persistence and Survival}

\subsection{Detection Methods}

Detection methods for $T$. gondii oocysts in the environment using bioassays, microscopy, and molecular assays are summarized in Table 1 and reviewed by (Dumetre and Darde, 2003; VanWormer, 2012). Immunofluorescent assays commonly employed to detect other waterborne protozoa, namely Cryptosporidium and Giardia oo(cysts), are described in the scientific literature (Dumetre and Darde, 2005; Dumetre and Darde, 2007), but are not commercially available for $T$. gondii. For detection of oocysts in water, concentration is required due to the relative dilute distribution of $T$. gondii in environmental water sources. Methods include membrane filtration, capsule filtration, hollow fiber ultrafiltration, flocculation, and centrifugation. A combination of water concentration via Fluoropore ${ }^{\circledR}$ membranes followed by bioassay has been successfully applied in Brazil to isolate T. gondii implicated in a large waterborne outbreak (de Moura et al., 2006), indicating that a combination of physical and biological approaches can be utilized for parasite identification even under challenging laboratory and field conditions.
For direct visualization of T. gondii, microscopical methods have capitalized on the autofluorescence nature of T. gondii oocyst and sporocyst walls, which fluoresce blue under ultraviolet (UV) excitation (Lindquist et al., 2003). While cost effective, methods that rely on microscopical identification require molecular confirmation to definitively identify oocysts as $T$. gondii, because other apicomplexan parasites have identical morphological appearance (e.g. Hammondia, Besnoitia, and Neospora oocysts). Isolation of

T. gondii from water using mouse bioassays provides definitive identification for viable parasites, but this approach is laborious, costly, and time-consuming. By contrast, molecular detection has been gaining steady recognition for sensitive and rapid detection of $T$. gondii oocysts, and methods include both conventional (end-point) and real-time, quantitative PCR. Additional molecular approaches using loop-mediated isothermal amplification (LAMP) have also been described (Sotiriadou and Karanis, 2008).

It is imperative that any molecular detection technique applied to environmental samples be followed by sequence analysis for definitive confirmation of $T$. gondii DNA due to potential for non-target amplification by flora and biota commonly present in both gut and environmental habitats even when using primers shown to be specific for T. gondii when compared with other coccidian or enteric pathogens (Shapiro et al., 2015; Lilly and Wortham, 2013). Although multiple methods for oocyst detection are described in the scientific literature, the lack of standardized assays for detection of oocysts in the environment has likely contributed to an underestimation of the significant role oocyst-borne infections play in the epidemiology of $T$. gondii in human and animal populations. 
Table 1. Published methods for concentration and detection of Toxoplasma gondii oocysts in water

\begin{tabular}{|c|c|c|c|c|c|}
\hline $\begin{array}{c}\text { Water } \\
\text { Tested }\end{array}$ & $\begin{array}{c}\text { Laboratory } \\
\text { or Field } \\
\text { Study }\end{array}$ & $\begin{array}{c}\text { Water } \\
\text { Concentration } \\
\text { Method }\end{array}$ & $\begin{array}{c}\text { T. gondii } \\
\text { Detection } \\
\text { Assay(s) }\end{array}$ & $\begin{array}{c}\text { Quantitative } \\
\text { Yes /No }\end{array}$ & Reference \\
\hline Tap, fresh & Laboratory & $\begin{array}{c}\text { Centrifugation } \\
\text { (ether/formalin } \\
\text { method) }\end{array}$ & $\begin{array}{c}\text { Microscopy and } \\
\text { PCR }\end{array}$ & No & $\begin{array}{c}\text { Lora-Suarez et al., } \\
\text { 2016; Trivino- } \\
\text { Valencia et al., } \\
2016\end{array}$ \\
\hline $\begin{array}{l}\text { Tap, } \\
\text { fresh, } \\
\text { marine }\end{array}$ & Laboratory & $\begin{array}{l}\text { Ultrafiltration } \\
\text { and capsule } \\
\text { filtration }\end{array}$ & $\begin{array}{l}\text { Microscopy, } \\
\text { PCR }^{\mathrm{a}}, \mathrm{qPCR}^{\mathrm{b}}\end{array}$ & Yes & $\begin{array}{l}\text { Shapiro et al., } \\
\text { 2010a }\end{array}$ \\
\hline Tap, fresh & Laboratory & $\begin{array}{l}\text { Continuous } \\
\text { separation } \\
\text { centrifugation }\end{array}$ & Microscopy & Yes & $\begin{array}{l}\text { Borchardt et al., } \\
2009\end{array}$ \\
\hline Fresh & Laboratory & $\begin{array}{l}\text { Capsule } \\
\text { filtration }\end{array}$ & qPCR & Yes & $\begin{array}{l}\text { Yang et al., } \\
2009\end{array}$ \\
\hline Fresh & $\begin{array}{l}\text { Laboratory } \\
\text { and field }\end{array}$ & $\begin{array}{l}\text { Capsule } \\
\text { filtration }\end{array}$ & $\begin{array}{c}\text { PCR, mouse } \\
\text { Bioassay }\end{array}$ & No & $\begin{array}{c}\text { Aubert and } \\
\text { Villena, } 2009\end{array}$ \\
\hline Fresh & $\begin{array}{l}\text { Laboratory } \\
\text { and field }\end{array}$ & $\begin{array}{l}\text { Flocculation } \mathrm{Al}_{2} \\
\quad\left(\mathrm{SO}_{4}\right)_{3}\end{array}$ & $\begin{array}{l}\text { Loop-mediated } \\
\text { isothermal } \\
\text { amplification }\end{array}$ & No & $\begin{array}{l}\text { Sotiriadou and } \\
\text { Karanis, } 2008\end{array}$ \\
\hline Tap, fresh & $\begin{array}{l}\text { Laboratory } \\
\text { and field }\end{array}$ & $\begin{array}{l}\text { Capsule } \\
\text { filtration }\end{array}$ & $\begin{array}{c}\text { Immunomagnetic } \\
\text { separation }\end{array}$ & Yes & $\begin{array}{l}\text { Dumetre and } \\
\text { Darde, 2005; } \\
\text { Dumetre and } \\
\text { Darde, } 2007\end{array}$ \\
\hline Tap & Field & $\begin{array}{l}\text { Membrane } \\
\text { filtration }\end{array}$ & $\begin{array}{c}\text { Bioassay } \\
\text { (chicken, cats, } \\
\text { mice, and pigs) }\end{array}$ & No & $\begin{array}{c}\text { de Moura et al., } \\
2006\end{array}$ \\
\hline $\begin{array}{l}\text { Tap, } \\
\text { fresh, } \\
\text { marine }\end{array}$ & $\begin{array}{l}\text { Laboratory } \\
\text { and field }\end{array}$ & $\begin{array}{l}\text { Flocculation } \\
\left(\mathrm{Al}_{2}\left(\mathrm{SO}_{4}\right)_{3}\right)\end{array}$ & PCR & No & $\begin{array}{l}\text { Kourenti and } \\
\text { Karanis, } 2006\end{array}$ \\
\hline $\begin{array}{l}\text { Deionized, } \\
\text { fresh }\end{array}$ & $\begin{array}{l}\text { Laboratory } \\
\text { and field }\end{array}$ & $\begin{array}{l}\text { Capsule } \\
\text { filtration }\end{array}$ & $\begin{array}{l}\text { PCR, mouse } \\
\text { bioassay }\end{array}$ & No & Villena et al., 2004 \\
\hline Fresh & Laboratory & $\begin{array}{c}\text { Flocculation } \mathrm{Al}_{2} \\
\left(\mathrm{SO}_{4}\right)_{3} \& \mathrm{Fe}_{2} \\
\left(\mathrm{SO}_{4}\right)_{3}\end{array}$ & PCR & No & $\begin{array}{c}\text { Kourenti and } \\
\text { Karanis, } 2004\end{array}$ \\
\hline $\begin{array}{l}\text { Deionized, } \\
\text { tap }\end{array}$ & Laboratory & $\begin{array}{l}\text { Centrifugation } \\
\text { and } \\
\text { Flocculation } \mathrm{Al}_{2} \\
\left(\mathrm{SO}_{4}\right)_{3} \& \mathrm{Fe}_{2} \\
\left(\mathrm{SO}_{4}\right)_{3}\end{array}$ & Microscopy & Yes & $\begin{array}{l}\text { Kourenti et al., } \\
2003\end{array}$ \\
\hline Tap & $\begin{array}{l}\text { Laboratory }^{\mathrm{c}} \\
\text { and field }\end{array}$ & $\begin{array}{l}\text { Capsule } \\
\text { filtration }\end{array}$ & Bioassay & No & $\begin{array}{c}\text { Isaac-Renton et } \\
\text { al., } 1998\end{array}$ \\
\hline
\end{tabular}




\subsection{Data on occurrence in the environment}

In domestic cats, hundreds of millions of oocysts can be excreted following initial exposure to T. gondii over a 1-3 week period (Dubey, 2001). Typically, domestic cats are thought to excrete only once following initial acute infection, though oocyst shedding can recure due to coinfection with other coccidian parasites (Chessum, 1972; Dubey, 1995), subsequent infection with different $T$. gondii strains (Dubey, 1995), or due to severe immunosuppression (Dubey and Frenkel, 1974; Dubey, 1976).

The prevalence of $T$. gondii oocysts in feces from domestic cats has been reported to range from $0-9 \%$ (as reviewed by (VanWormer et al., 2013b). In wild felids, higher prevalences of oocysts in feces have been reported, ranging from 0-37\% (Marchiondo et al., 1976; Pizzi et al., 1978)(Pizzi et al., 1978). Higher prevalences of fecal shedding and sero-exposure to $T$. gondii have also been reported in unmanaged feral domestic cats not receiving supplemental feeding from people (VanWormer et al., 2013a). Reliance on intermediate hosts as a source of food, coinfection with other intestinal parasites, and re-exposure to multiple $T$. gondii strains over their lifetime are all factors that are likely to contribute to the higher prevalence of fecal shedding observed in wild and truly feral cats.

Schares et al., (2016) reported the importance of seasonality in the proportions of domestic cats shedding $T$. gondii, and the association of shedding with climatic factors. In their study, a model incorporating temperature and North Atlantic Oscillation indices was able to predict the proportion of cats shedding T. gondii over the year. These and previous findings (Meerburg and Kijlstra 2009) suggest that global warming may influence infection risk of animals and humans with $T$. gondi.

\subsubsection{Raw sewage, treated effluents and sludge}

One would not expect oocysts of $T$. gondi to be in sewage, however due to storm water or households dumping cat feces into the toilet there is a possibility that this parasite could be found in sewer systems. Reports on attempted and/or positive detection of $T$. gondii in sewage or sludge are scarce. However, given the robust nature of oocyst survival under a range of chemical and physical insults, there exists a definite threat for contamination of these matrices with viable $T$. gondii parasites. This threat has been recognized by both academic institutions (Frenkel and Dubey, 1972; Bowman and Fayer, 2005), as well as public health agencies (EPA, 1989; Carrington, 2001). Investigations targeting detection of $T$. gondii in sewage treatment plants receiving municipal waste and/or storm water runoff (where cat feces is expected to be present) are needed to evaluate presence and distribution of oocysts within the different components of wastewater processing steps. A serious challenge to such investigations lies in the difficulty of applying sensitive detection tools (such as PCR) to difficult matrices that are known to contain organic constituents that can inhibit parasite DNA amplification. Thus, improvement of methodologies for $T$. gondii detection, combined with parasite viability assessment, is an essential step for investigating parasite distribution and survival within wastewater treatment facilities.

Few investigations have targeted detection of $T$. gondii in wastewater (Table 2). In Germany, T. gondii DNA was detected using loop mediated isothermal amplification (LAMP; a single tube technique for the amplification) in $8.9 \%$ of wastewater influent and in $10.5 \%$ of wastewater effluent samples. When both LAMP and PCR were used for detection, $43 \%$ of sewage samples from Bulgaria were found positive for $T$. gondii. However, $T$. gondii was not detected in wastewater in France and Italy (Moulin et al., 2010; Marangi et al., 2015; Kerambrun et al., 2016b). An innovative approach for monitoring for $T$. gondii in wastewater effluent-receiving water bodies was recently proposed using zebra mussels as sentinels (Kerambrun et al., 2016a). There are no data regarding T. gondii in wastewater from aquaculture operations. 
Table 2. Occurrence of Toxoplasma in sewage

\begin{tabular}{|c|c|c|c|c|}
\hline Area & Matrices Analyzed & $\begin{array}{l}\text { Percent Posivite } \\
\text { (\# Samples) }\end{array}$ & $\begin{array}{c}\text { Detection Assay(s) } \\
\text { Used }^{\mathrm{a}}\end{array}$ & Reference \\
\hline Bulgaria & Sewage & $\begin{array}{l}43 \% \\
(3 / 7)\end{array}$ & $\mathrm{LAMP}^{\mathrm{b}} \& \mathrm{PCR}^{\mathrm{c}}$ & $\begin{array}{c}\text { Sotiriadou and } \\
\text { Karanis, } 2008\end{array}$ \\
\hline Germany & $\begin{array}{c}\text { Sewage } \\
\text { (Influent) }\end{array}$ & $\begin{array}{l}8.9 \% \\
(4 / 45)\end{array}$ & LAMP & $\begin{array}{l}\text { Gallis-Lindemann } \\
\text { et al., } 2013\end{array}$ \\
\hline Germany & $\begin{array}{l}\text { Sewage } \\
\text { (Effluent) }\end{array}$ & $\begin{array}{l}10.5 \% \\
(4 / 38)\end{array}$ & LAMP & $\begin{array}{l}\text { Gallis-Lindemann } \\
\text { et al., } 2013\end{array}$ \\
\hline Greece & Sewage & $\begin{array}{l}0 \% \\
(0 / 7)\end{array}$ & LAMP & $\begin{array}{l}\text { Kourenti and } \\
\text { Karanis, } 2006\end{array}$ \\
\hline Japan & Sewage & $\begin{array}{c}33.3 \% \\
(1 / 3)\end{array}$ & LAMP & $\begin{array}{l}\text { Kourenti and } \\
\text { Karanis, } 2006\end{array}$ \\
\hline
\end{tabular}

\subsubsection{Surface water}

Numerous investigations have found T. gondii in surface waters (Table 3). Contamination levels range from 0-9\% prevalence of samples that test positive for the parasite in developed countries (France, Germany, Scotland), and up to $77 \%$ prevalence of detection in low-middle income countries (e.g. Colombia). As previously discussed, sequence confirmation of any suspect samples that test positive for $\mathrm{T}$. gondii using molecular methods (conventional or real time PCR as well as LAMP) is imperative for definitive detection of the parasite.
Amplification of non-target DNA by environmental flora or biota has been commonly reported despite the apparent specificity of primer sets when tested against other known pathogens (Shapiro et al., 2015; Lilly and Wortham, 2013). Few studies have included DNA sequence confirmation in environmental water samples. 
Table 3. Occurrence of Toxoplasma in surface water

\begin{tabular}{|c|c|c|c|c|}
\hline Area & $\begin{array}{c}\text { Percent Positive } \\
\text { (\# of Samples) }\end{array}$ & $\begin{array}{c}\text { Concentration } \\
\text { Method }\end{array}$ & Detection Assay(s) Used & Reference \\
\hline Bulgaria & $\begin{array}{c}12.5 \% \\
(1 / 8)\end{array}$ & $\begin{array}{c}\text { flocculation } \\
\left(\mathrm{Al}_{2}\left(\mathrm{SO}_{4}\right)_{3}\right)\end{array}$ & $\mathrm{PCR}^{\mathrm{a}}$ & $\begin{array}{l}\text { Kourenti and } \\
\text { Karanis, } 2006\end{array}$ \\
\hline Bulgaria & $\begin{array}{l}64.3 \% \\
(9 / 14)\end{array}$ & $\begin{array}{l}\text { flocculation } \\
\left(\mathrm{Al}_{2}\left(\mathrm{SO}_{4}\right)_{3}\right)\end{array}$ & $\mathrm{LAMP}^{\mathrm{b}} \& \mathrm{PCR}$ & $\begin{array}{l}\text { Sotiriadou and } \\
\text { Karanis, } 2008\end{array}$ \\
\hline Colombia & $\begin{array}{c}76.9 \% \\
(10 / 13)\end{array}$ & centrifugation & $\mathrm{PCR}^{\mathrm{c}}$ & $\begin{array}{l}\text { Trivino-Valencia } \\
\text { et al., } 2016\end{array}$ \\
\hline France & $\begin{array}{c}6.7 \% \\
(3 / 45)\end{array}$ & $\begin{array}{l}\text { capsule } \\
\text { filtration }\end{array}$ & PCR \& mouse bioassay ${ }^{\mathrm{d}}$ & $\begin{array}{l}\text { Villena et al., } \\
2004\end{array}$ \\
\hline France & $\begin{array}{c}7.7 \% \\
(37 / 482)\end{array}$ & $\begin{array}{l}\text { flocculation } \\
\left(\mathrm{Al}_{2}\left(\mathrm{SO}_{4}\right)_{3}\right)\end{array}$ & PCR \& mouse bioassay & $\begin{array}{c}\text { Aubert and } \\
\text { Villena, } 2009\end{array}$ \\
\hline Germany & $\begin{array}{c}0 \% \\
(0 / 7)\end{array}$ & $\begin{array}{l}\text { flocculation } \\
\left(\mathrm{Al}_{2}\left(\mathrm{SO}_{4}\right)_{3}\right)\end{array}$ & LAMP & $\begin{array}{l}\text { Gallas-Lindemann } \\
\text { et al., } 2013\end{array}$ \\
\hline Greece & $\begin{array}{c}0 \% \\
(0 / 14)\end{array}$ & $\begin{array}{l}\text { flocculation } \\
\left(\mathrm{Al}_{2}\left(\mathrm{SO}_{4}\right)_{3}\right)\end{array}$ & PCR & $\begin{array}{l}\text { Kourenti and } \\
\text { Karanis, } 2006\end{array}$ \\
\hline Iran & $\begin{array}{l}5.9 \% \\
(2 / 34)\end{array}$ & $\begin{array}{l}\text { membrane } \\
\text { filtration }\end{array}$ & $\begin{array}{l}\text { LAMP } \\
\text { qPCR }\end{array}$ & $\begin{array}{l}\text { Mahmoudi et al., } \\
2015\end{array}$ \\
\hline Japan & $\begin{array}{c}0 \% \\
(0 / 6)\end{array}$ & $\begin{array}{l}\text { flocculation } \\
\left(\mathrm{Al}_{2}\left(\mathrm{SO}_{4}\right)_{3}\right)\end{array}$ & LAMP & $\begin{array}{c}\text { Kourenti and } \\
\text { Karanis, } 2006\end{array}$ \\
\hline Pakistan & $\begin{array}{c}7 \% \\
(7 / 100)\end{array}$ & $\begin{array}{l}\text { membrane } \\
\text { filtration and } \\
\text { centrifugation }\end{array}$ & PCR & Khan et al., 2013 \\
\hline Russia & $\begin{array}{l}53.3 \% \\
(8 / 15)\end{array}$ & $\begin{array}{l}\text { flocculation } \\
\left(\mathrm{Al}_{2}\left(\mathrm{SO}_{4}\right)_{3}\right)\end{array}$ & $\begin{array}{l}\text { LAMP } \\
\text { PCR }\end{array}$ & $\begin{array}{l}\text { Sotiriadou and } \\
\text { Karanis, } 2008\end{array}$ \\
\hline Scotland & $\begin{array}{c}8.8 \% \\
(124 / 1427)\end{array}$ & $\begin{array}{l}\text { flocculation } \\
\left(\mathrm{Al}_{2}\left(\mathrm{SO}_{4}\right)_{3}\right)\end{array}$ & PCR (ITS1) \& qPCR ${ }^{\mathrm{e}}$ & Wells et al., 2015 \\
\hline Turkey & $\begin{array}{c}13.2 \% \\
(10 / 76)\end{array}$ & $\begin{array}{l}\text { flocculation } \\
\left(\mathrm{Al}_{2}\left(\mathrm{SO}_{4}\right)_{3}\right)\end{array}$ & LAMP \& PCR & $\begin{array}{c}\text { Demirel et al., } \\
2014\end{array}$ \\
\hline Turkey & $\begin{array}{c}51.6 \% \\
(16 / 31)\end{array}$ & $\begin{array}{c}\text { flocculation } \\
\left(\mathrm{Al}_{2}\left(\mathrm{SO}_{4}\right)_{3}\right)\end{array}$ & LAMP \& PCR ${ }^{\mathrm{e}, \mathrm{f}}$ & $\begin{array}{c}\text { Koloren and } \\
\text { Demirel, } 2013\end{array}$ \\
\hline
\end{tabular}

${ }^{a}$ Polymerase Chain Reaction; ${ }^{b}$ Loop-mediated isothermal amplification; ${ }^{\mathrm{c}}$ Confirmed with sequence information; ${ }^{\mathrm{d}}$ Mouse bioassay attempted butT. gondii detected only via PCR; ${ }^{\mathrm{e}}$ Partial confirmation performed to definitively identify amplicons as $T$. gondii using sequence analysis $(\mathrm{n}=6) ;{ }^{\mathrm{f}}(\mathrm{n}=13)$

\subsubsection{Groundwater and drinking water}

T. gondii DNA has been reported in groundwater in Russia, Bulgaria, Pakistan, Poland, and France (Table 4). Sequence confirmation of suspected positive samples was not provided in a Brazilian ground water study (Vieira et al., 2015). Several studies have reported T. gondii DNA in drinking water in Bulgaria, Pakistan, Colombia, and France (Table 4). Confirmation of positive samples via sequence analysis was provided in a study conducted in Colombia, with widespread contamination of drinking water (52\% prevalence). Information on the range of concentrations of T. gondii oocysts in contaminated drinking water samples have not been reported (Bahia-Oliveira et al., 2003; de Moura et al., 2006; Trivino-Valencia et al., 2016). 
Table 4. Occurrence of Toxoplasma gondii in groundwater and tap water

\begin{tabular}{|c|c|c|c|c|}
\hline Area & $\begin{array}{c}\text { Percent } \\
\text { Positive } \\
\text { (\# } \\
\text { Samples) }\end{array}$ & $\begin{array}{c}\text { Concentration } \\
\text { Method }\end{array}$ & $\begin{array}{l}\text { Detection } \\
\text { Assay(s) } \\
\text { Used }\end{array}$ & Reference \\
\hline \multicolumn{5}{|c|}{ Groundwater } \\
\hline Bulgaria & $\begin{array}{l}14.4 \% \\
(1 / 7)\end{array}$ & $\begin{array}{l}\text { Flocculation } \\
\left(\mathrm{Al}_{2}\left(\mathrm{SO}_{4}\right)_{3}\right)\end{array}$ & $\mathrm{PCR}^{\mathrm{a}}$ & $\begin{array}{l}\text { Kourenti and } \\
\text { Karanis, } 2006\end{array}$ \\
\hline Bulgaria & $\begin{array}{l}50 \% \\
(3 / 6)\end{array}$ & $\begin{array}{c}\text { Flocculation } \\
\left(\mathrm{Al}_{2}\left(\mathrm{SO}_{4}\right)_{3}\right)\end{array}$ & LAMP $^{b} \&$ PCR & $\begin{array}{l}\text { Sotiriadou and } \\
\text { Karanis, } 2008\end{array}$ \\
\hline Germany & $\begin{array}{c}0 \% \\
(0 / 4)\end{array}$ & $\begin{array}{l}\text { Flocculation } \\
\left(\mathrm{Al}_{2}\left(\mathrm{SO}_{4}\right)_{3}\right)\end{array}$ & LAMP & $\begin{array}{l}\text { Gallas-Lindemann } \\
\text { et al., } 2013\end{array}$ \\
\hline Japan & $\begin{array}{c}0 \% \\
(0 / 3)\end{array}$ & $\begin{array}{l}\text { Flocculation } \\
\left(\mathrm{Al}_{2}\left(\mathrm{SO}_{4}\right)_{3}\right)\end{array}$ & LAMP & $\begin{array}{c}\text { Kourenti and } \\
\text { Karanis, } 2006\end{array}$ \\
\hline Pakistan & $\begin{array}{r}7.5 \% \\
(3 / 40)\end{array}$ & $\begin{array}{l}\text { Membrane } \\
\text { filtration and } \\
\text { centrifugation }\end{array}$ & PCR & Khan et al., 2013 \\
\hline Poland & $\begin{array}{c}27.2 \% \\
(31 / 114)\end{array}$ & $\begin{array}{l}\text { Membrane } \\
\text { filtration }\end{array}$ & Microscopy\& PCR & Sroka et al., 2006 \\
\hline Russia & $\begin{array}{c}100 \% \\
(1 / 1)\end{array}$ & $\begin{array}{c}\text { Flocculation } \\
\left(\mathrm{Al}_{2}\left(\mathrm{SO}_{4}\right)_{3}\right)\end{array}$ & $\begin{array}{l}\text { LAMP } \\
\text { PCR }\end{array}$ & $\begin{array}{l}\text { Sotiriadou and } \\
\text { Karanis, } 2008\end{array}$ \\
\hline \multicolumn{5}{|c|}{ Tap Water } \\
\hline Bulgaria & $\begin{array}{c}8.3 \% \\
(1 / 12)\end{array}$ & $\begin{array}{l}\text { Flocculation } \\
\left(\mathrm{Al}_{2}\left(\mathrm{SO}_{4}\right)_{3}\right)\end{array}$ & PCR & Sotiriadou and Karanis, 2008 \\
\hline Bulgaria & $\begin{array}{l}33.3 \% \\
(3 / 9)\end{array}$ & $\begin{array}{l}\text { Flocculation } \\
\left(\mathrm{Al}_{2}\left(\mathrm{SO}_{4}\right)_{3}\right)\end{array}$ & $\begin{array}{l}\text { LAMP \& } \\
\quad \text { PCR }\end{array}$ & Sotiriadou and Karanis, 2008 \\
\hline Colombia & $\begin{array}{r}51.5 \% \\
(17 / 33)\end{array}$ & Centrifugation & $\mathrm{PCR}^{\mathrm{c}}$ & Trivino-Valencia et al., 2016 \\
\hline Germany & $\begin{array}{c}0 \% \\
(0 / 1)\end{array}$ & $\begin{array}{l}\text { Flocculation } \\
\left(\mathrm{Al}_{2}\left(\mathrm{SO}_{4}\right)_{3}\right)\end{array}$ & LAMP & Gallas-Lindemann et al., 2013 \\
\hline Pakistan & $\begin{array}{r}3.3 \% \\
(2 / 60)\end{array}$ & $\begin{array}{l}\text { Membrane } \\
\text { filtration and } \\
\text { centrifugation }\end{array}$ & PCR & Khan et al., 2013 \\
\hline Turkey & $\begin{array}{c}0 \% \\
(0 / 20)\end{array}$ & $\begin{array}{l}\text { Flocculation } \\
\left(\mathrm{Al}_{2}\left(\mathrm{SO}_{4}\right)_{3}\right)\end{array}$ & $\begin{array}{l}\text { LAMP \& } \\
\quad \text { PCR }\end{array}$ & Demirel et al., 2014 \\
\hline Turkey & $\begin{array}{c}0 \% \\
(0 / 25)\end{array}$ & $\begin{array}{l}\text { Flocculation } \\
\left(\mathrm{Al}_{2}\left(\mathrm{SO}_{4}\right)_{3}\right)\end{array}$ & $\begin{array}{l}\text { LAMP \& } \\
\text { PCR }^{\mathrm{d}}\end{array}$ & Koloren and Demirel, 2013 \\
\hline
\end{tabular}

${ }^{a}$ Polymerase Chain Reaction; ${ }^{\mathrm{b}}$ Loop-mediated isothermal amplification; ${ }^{\mathrm{c}}$ Detection was confirmed with sequence confirmation; ${ }^{\mathrm{d}}$ Partial confirmation $(\mathrm{n}=13)$ were definitively identified as $T$. gondii using sequence analysis.

\subsubsection{Seawater and shellfish}

Few investigations have attempted to test seawater for the presence of T. gondii. T. gondii oocyst-like structures observed in estuarine waters in the Galapagos Islands could not be molecularly confirmed (Verant et al., 2014). An alternative approach for detection of $T$. gondii in marine ecosystems targets testing of filter-feeding bivalves as sentinels for pollution and has found marine ecosystem contamination with $T$. gondii in various countries, including the USA, Turkey, Brazil, and China (Esmerini et al., 2010; Miller et al., 2008; Putignani et al., 2011; Shapiro et al., 2015; Staggs et al., 2015; Aksoy et al., 2014; Zhang et al., 2014). Contaminated wild and/or commercially purchased shellfish have been reported (Table 5). To date, standardized methods have not been developed for detection of $T$. gondii in bivalve or fish tissues, with most studies utilizing variable molecular assays, and testing different matrices, including whole tissue homogenates, gastrointestinal tissue, gills, and/or hemolymph. Further studies on isolation and genotyping of $T$. gondii from fishes are necessary to better understand the role of seafood in the transmission of T. gondii infection. Migratory filter feeding fishes, namely, northern anchovies (Engraulis mordax) and Pacific sardines (Sardinops sagax) can harbor T. gondii oocysts and transmit the infection to other animals under experimental conditions. These findings suggest that $T$. gondii can be transmitted by fish throughout the oceans (Massie et al., 2010). 
Table 5. Occurrence of Toxoplasma gondii in fish and shellfish

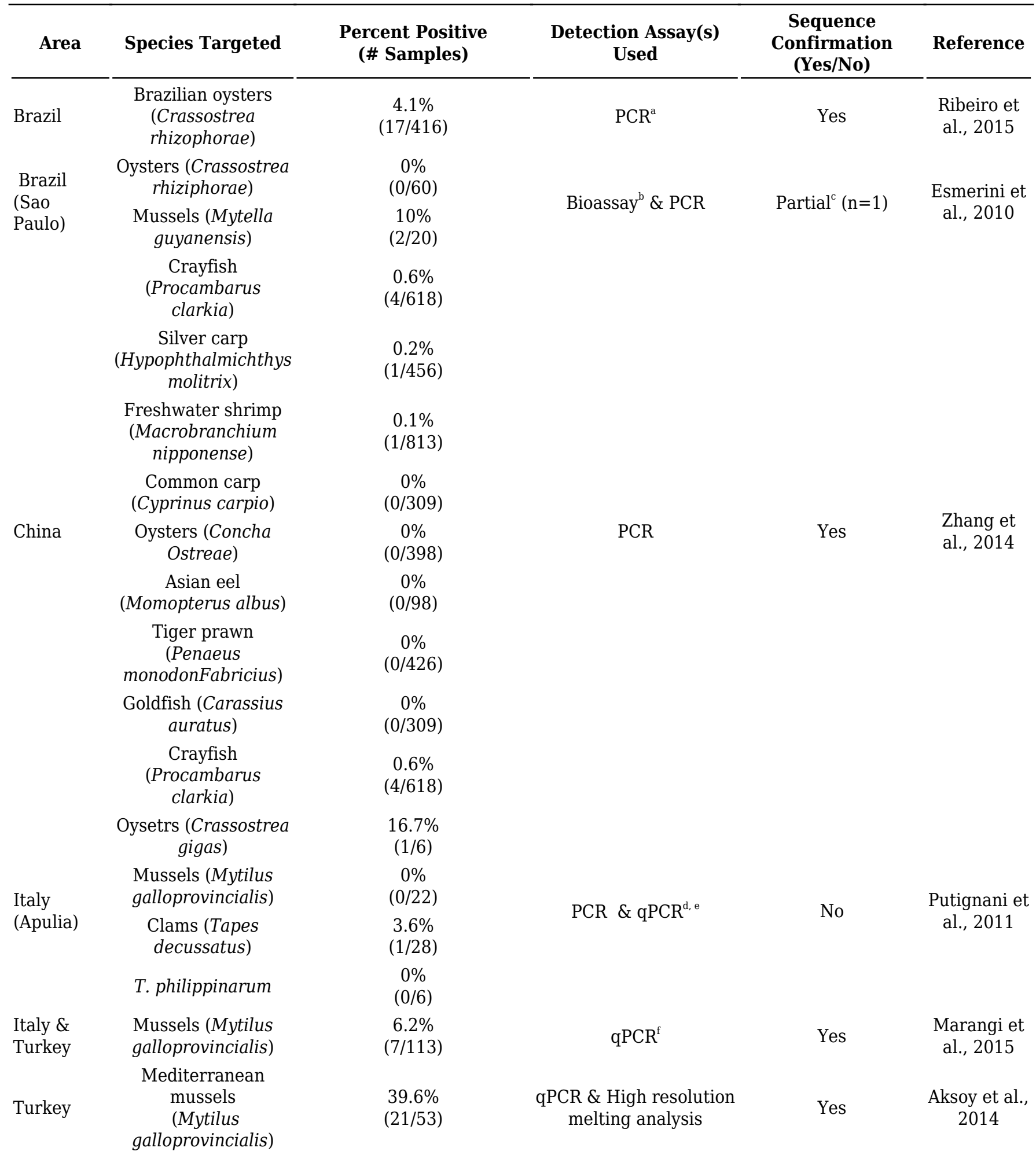




\begin{tabular}{|c|c|c|c|c|c|}
\hline Area & Species Targeted & $\begin{array}{l}\text { Percent Positive } \\
\text { (\# Samples) }\end{array}$ & $\begin{array}{c}\text { Detection Assay(s) } \\
\text { Used }\end{array}$ & $\begin{array}{c}\text { Sequence } \\
\text { Confirmation } \\
\text { (Yes/No) } \\
\end{array}$ & Reference \\
\hline \multirow{4}{*}{$\begin{array}{l}\text { USA } \\
\text { (California) }\end{array}$} & $\begin{array}{c}\text { California mussels } \\
\text { (Mytilus } \\
\text { californianus) }\end{array}$ & $\begin{array}{c}0.09 \% \\
(1 / 1,109)\end{array}$ & & & \\
\hline & $\begin{array}{c}\text { Sand crabs (Emerita } \\
\text { analoga), } \\
\text { Gaper clams } \\
\text { (Tresusnuttallii), } \\
\text { Pismo clams (Tivela } \\
\text { stultorum), } \\
\text { Fat innkeeper worms } \\
\text { (Urechis caupo) }\end{array}$ & $\begin{array}{c}0 \% \\
(0 / 287)\end{array}$ & qPCR & Yes & $\begin{array}{l}\text { Miller et } \\
\text { al., } 2008\end{array}$ \\
\hline & $\begin{array}{c}\text { California mussels } \\
\text { (Mytilus } \\
\text { californianus) }\end{array}$ & $\begin{array}{c}1.4 \% \\
(13 / 959)\end{array}$ & PCR & Yes & $\begin{array}{l}\text { Shapiro et } \\
\text { al., } 2015\end{array}$ \\
\hline & $\begin{array}{l}\text { Mussels (Mytilus } \\
\text { californianus/ } \\
\text { galloprovincialis/ } \\
\text { trossulus/edulis) }\end{array}$ & $\begin{array}{l}46.3 \% \\
(19 / 41)\end{array}$ & PCR \& qPCR ${ }^{f}$ & Yes & $\begin{array}{l}\text { Staggs et } \\
\text { al., } 2015\end{array}$ \\
\hline
\end{tabular}

${ }^{a}$ Polymerase chain reaction (conventional, end-point); ${ }^{\mathrm{b}}$ Detection attempted using bioassays in mice and PCR with successful detection of T. gondii only via PCR; 300 mussels or oysters were tested in batches of 5 or 15 animals, respectively; ${ }^{\mathrm{c}}$ Partial confirmation denotes the number of positive samples that were definitively identified as $T$. gondii using sequence analysis; ${ }^{d}$ Real-time quantitative PCR; ${ }^{e}$ Detection of T. gondii in field collected mussels was attempted using both conventional and real-time PCR assays, but only successful when conventional PCR was applied; ${ }^{\mathrm{f}}$ Multiplex realtime PCR assay for T. gondii, Cryptosporidium, and Giardia. The same study also evaluated 119 wastewater samples but all tested negative for T. gondii.

Prevalences of shellfish contamination range from a low of $0.07 \%(1 / 1396)$ (Miller et al., 2008) to a high of $54 \%$ $(14 / 26)$ (Staggs et al., 2015). Sequence data have confirmed T. gondii in a wide range of marine fish and shellfish, highlighting the importance of seafood as a potential source of infection for both aquatic wildlife and people. Consumption of raw shellfish has been epidemiologically associated with $T$. gondii infection in people (Jones et al., 2009).

Distribution of $T$. gondii genotypes characterized in aquatic invertebrates include the archetypal Type I (California, Turkey and Italy) (Shapiro et al., 2015; Aksoy et al., 2014; Marangi et al., 2015), Type II (California) (Shapiro et al., 2015), as well as atypical genotypes including Type $\mathrm{X}$ which has been implicated as a cause of mortality in threatened California sea otters (Shapiro et al., 2015; Miller et al., 2004; Miller et al., 2008). The ability of zebra mussels to bioconcentrate $T$. gondii has been proposed as a tool for monitoring freshwater bodies for contamination with the parasite (Palos Ladeiro et al., 2014).

\subsubsection{Crops and soil}

The distribution of $T$. gondii contamination of soil and/or water and subsequent contamination of crops remains an unanswered question. The first report of soil contaminated with T. gondii was in 1973 based on a mouse bioassay that demonstrated the parasite in 4 of 15 (26.7\%) soil samples collected in Costa Rica (Ruiz et al., 1973). Additional studies using bioassay found the parasite in $20 \%$ $(1 / 5)$ garden soil samples in Brazil (Coutinho et al., 1982), in $1.1 \%(10 / 924)$ soil samples collected from Panama (Frenkel et al., 1995), and in Japan (unspecified number of samples (Ito et al., 1975). Another bioassay study in Brazil demonstrated $22.58 \%$ (7/31) of soil samples from school playgrounds positive for T. gondii (dos Santos et al., 2010). Of 150 soil samples tested in Iran, 13 samples were PCR positive for T. gondii DNA (8.7\%), and consisted of Types I and III (Tavalla et al., 2013). Toxoplasma gondii DNA was detected by real-time PCR in $29.9 \%(n=243)$ of soil samples collected from a rural area in eastern France (Gotteland et al., 2014). In Poland, PCR detected $17.8 \%$ (18/101) contaminated soil samples with subsequent genotyping revealing Types I and II (Lass et al., 2009). Although investigations have not provided quantitative estimates regarding concentrations of oocysts in contaminated soil, modeling approaches have estimated annual contamination to range between 31 and 3,600 oocysts/m2 in rural France (Afonso et al., 2010), and 94-4,671 oocysts/m2 in California, USA (Dabritz et al., 2007).

There are no reports of attempted or positive detection of T. gondii in irrigation water. However, crops have been found contaminated with the parasite. In Pakistan 1.9\% $(n=500)$ of vegetables tested positive for $T$. gondii (Shafa ul et al., 2014), based only microscopy for detection and no molecular confirmation. Microscopy was also used to find 
$6.6 \%$ T. gondii contamination of leafy green vegetables in Saudi Arabia, (Al-Megrin, 2010) and in 4.9\% of vegetables in Egypt, but molecular confirmation was again lacking (Ahmad et al., 2016). The only study in which molecular methods were applied was in Poland, where 9.7\% (21/216) of fruits and vegetables tested positive via quantitative PCR with genotypes I and II (Lass et al., 2012). While few studies have attempted to detect $T$. gondii on irrigation waters and/or produce, the importance of contaminated crops as means for transmission of this parasite should not be underestimated. Consumption of unwashed fruits and vegetables has been epidemiologically linked to infections in people (Slifko et al., 2000; Jones and Dubey, 2012), and thus improved detection methods and standardized approaches that could be adopted by the produce industry would be prudent for appropriate monitoring to insure provision of safe produce to consumers.

\subsection{Persistence}

Toxoplasma gondii oocysts are remarkably robust and can survive for long durations under diverse environmental conditions (as reviewed by (Dumetre and Darde, 2003). In cold freshwater $\left(4^{\circ} \mathrm{C}\right)$, oocysts can remain infectious for at least 54 months (Dubey, 1998b), while in seawater T. gondii can remain viable for at least 24 months (Lindsay and Dubey, 2009). Rainy seasons are also correlated with higher infection rates in humans (Gómez-Marin et al., 2011; Rudzinski et al., 2013; Tizard et al., 1976), and rainy winters combined with mild winter temperatures should favor oocyst survival (Afonso et al. 2010).The parasite can retain infectivity within shellfish for at least 85 days in oysters (Lindsay et al., 2004) and 3 days in mussels (Arkush et al., 2003). Oocysts retained viability in both dry and moist soil samples from Costa Rica over one year, and in soil from Kansas viability persisted over 18 months (Frenkel et al., 1975). A more recent study from France demonstrated that after 100 days, $1.13 \log _{10}$ reduction of oocyst infectivity (7.4\% remained viable) in soil under dry conditions as compared with only $0.36 \log _{10}$ reduction of oocyst infectivity (43.7\% remained viable) in soil kept damp (Lelu et al., 2012).

High temperatures negatively affect the viability of $T$. gondii (Dubey, 1998b), although some oocysts can remain infectious over a range of environmental temperatures $\left(10-25^{\circ} \mathrm{C}\right)$ for at least 200 days. At $40^{\circ} \mathrm{C} \mathrm{T}$. gondii is rendered non-viable within 28 days. Exposure of oocysts to $60^{\circ} \mathrm{C}$ reduced infectivity within one minute. Higher temperatures for longer durations may be required for complete and reliable inactivation. At $-21^{\circ} \mathrm{C}, \mathrm{T}$. gondii persisted for up to 28 days (Frenkel and Dubey, 1973). In feces, oocysts have also retained viability under a range of temperatures $\left(-6^{\circ} \mathrm{C}\right.$ to $\left.39^{\circ} \mathrm{C}\right)$ for $45-410$ days (Yilmaz and Hopkins, 1972).

\subsection{Reductions by Sanitation Management}

\subsection{Excreta and Wastewater treatment}

\subsubsection{Composting of fecal wastes}

There are no data on T. gondii oocysts in compost of fecal origin. However, the possibility of large numbers of $T$. gondii oocyst in waste that include feline feces is a real and recognized threat to the contamination of water, soil, and vegetables, with consequence that include livestock exposure. There are no data on oocyst viability under natural conditions associated with sludge and composting materials. As previously discussed, oocysts can survive in felid feces buried in soil for as long as 18 months under temperatures varying from 15 to $35^{\circ} \mathrm{C}$ (Frenkel et al., 1975). Thus, investigations targeting the presence of $T$. gondii oocysts in compost containing felid feces are essential to assess the potential threat of this matrix as an exposure vehicle to humans and animals.

\subsubsection{Wetlands}

There are no data on the ability of wetlands constructed specifically for treating wastewater to reduce the presence of $T$. gondii oocysts in effluent waters. Investigations on the ability of wetland habitats to reduce oocyst transport under natural conditions have demonstrated the beneficial role these systems have on reducing downstream contamination. Degradation of estuarine wetlands has been shown to increase the flux of $T$. gondii oocysts in effluent waters by 6 orders of magnitude, with both flow velocity and presence of vegetation having significant impact on oocyst transport (Shapiro et al., 2010a). Additional studies evaluating the role of coastal wetlands in reducing T. gondii contamination have determined that increased water salinity and presence of vegetation are associated with reduced oocyst transport in effluent waters (Hogan et al., 2013; Daniels et al., 2014).

\subsubsection{Wastewater Treatment}

\subsubsection{Primary treatment with biocoagulants}

Large scale experiments to investigate and understand T. gondii distribution and survival within wastewater treatment facilities and water distribution systems worldwide (in developed or developing countries) have not been reported. Such experiments are essential for evaluating the application of oocyst detection methods, transport, viability, and infectivity of the parasite throughout wastewater facilities. These investigations are also critical for determining efficient oocyst removal/inactivation steps that could be adopted by the local wastewater practices, and accurately assessing risk of exposure. Newly targeted research might provide specific options for prevention measures available in developed as well as developing countries. For example, in developing countries, wastewater treatment facilities have limited resources, and there is continous contamination of water sources from untreated or poorly treated wastewater (Yongabi, 2015).

In this context, the use of chemical coagulants may be limited due to cost in more resrouce-strained countries, whereas the use of biocoagulants can become an affordable 
alternative. Promising results using powdered Moringa oleifera seeds as an integrated low-technology biocoagulant-sand filter drum for removal of $T$. gondii oocysts have been described. Tests at bench and pilot field scale levels in Mezan River waters in Cameroon, Subsaharan Africa (Yongabi and Knoll, 2015), monitored by microscopy, found elimination of $T$. gondii oocysts; however, the study did not provide experimental data on the infectivity of oocysts in the treated waters by means of bioassays, or definitive confirmation of the identity of oocysts via PCR (Yongabi and Knoll, 2015).

\subsubsection{Coagulation}

The ability of commonly used coagulants to destabilize T. gondii oocysts has not been described in the context of wastewater or drinking water treatment. However several studies have utilized coagulation agents to improve oocyst isolation for detection of the parasite in water sources. The most commonly described coagulants in these studies are ferrous and aluminum sulfate (Kourenti et al., 2003; Kourenti and Karanis, 2004; Kourenti and Karanis, 2006; Lass et al., 2012). Experiments that evaluated the efficiency of these two agents on recovery of $T$. gondii oocysts in water have determined that aluminum sulfate provides the most efficient recovery of oocysts with up to $96 \%$ of spiked oocysts recovered through flocculation (Kourenti et al., 2003). This study further determined that T. gondii oocysts remain infectious following flocculation with common coagulation agents, further demonstrating their ability to persist through commonly employed water treatment processes.

\subsubsection{Filtration}

Several filtration processes have been evaluated in studies optimizing detection methods for T. gondii in water.

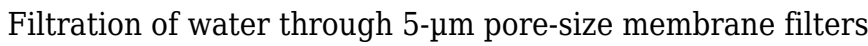
(microfiltration) has been shown to retain T. gondii oocysts that were spiked into fresh or marine waters, which can then be visualized using epifluorescent microscopy (Shapiro et al., 2010b). The same study simultaneously evaluated ultrafiltration and capsule filtration for recovery of oocysts in spiked water samples and determined both filtration methods yielded similar recovery efficiencies of oocysts in contaminated tap, fresh, and seawater samples. However, the ability of different membrane filtration techniques to remove $T$. gondii oocysts in the context of drinking or wastewater treatment has not been described. There are no data on the ability of reverse osmosis filtration to remove $T$. gondii oocysts.

\subsection{Disinfection}

\subsubsection{Chlorine and ozone}

Experimental results evaluating the viability of T. gondii oocysts following exposure to sodium hypochlorite or ozone indicate that neither disinfection strategy effectively or reliably inactivated oocysts, even at high concentrations, as determined by mouse bioassay, serology, immunohistochemistry, and by in vitro parasite isolation.
Viable infections in mice were observed even after exposing oocysts to high concentrations of chlorine $(100 \mathrm{mg} / \mathrm{L}$ of chlorine) or high doses of ozone $(6 \mathrm{mg} / \mathrm{L})$ treatment (Wainwright et al., 2007b). In contrast, it was reported that Cryptosporidum parvum oocysts are inactivated $\left(>2 \log _{10}\right)$ following exposure to 3 or $4 \mathrm{mg} / \mathrm{L}$ of ozone (Finch et al., 1993). Differences in ozone susceptibility between T. gondii and $C$. parvum might be attributed to differences in oocyst wall composition.

Exposing cat feces containing T. gondii oocysts to $5.25 \%$ aqueous sodium hypochlorite for $24 \mathrm{hr}$ also failed to kill the oocysts (Dubey et al., 1970). Purified oocysts allow for increased interaction between the chlorine and the oocyst, whereas chlorine reacting with the organic components of the cat feces reduces its effectiveness. The experimental results indicate that $T$. gondii oocysts in either sewage or drinking water disinfected with chlorine at standard dosages, will likely remain viable.

The physicochemical properties of the T. gondii oocyst wall that impart such strong chemical resistance have been investigated by combining wall surface treatments, fluorescence imaging, electronic microscopy, and measurements of its mechanical characteristics by atomic force microscopy. Results on elasticity and indentation measurements indicated that the oocyst wall resembles common plastic materials (Dumètre et al., 2013), implying that the oocyst wall mechanics play a key biological role in maintaining the integrity of the oocysts in the environment and impart resistance to disinfectants.

\subsubsection{Irradiation and UV disinfection}

The disinfection effect of alfa and gamma irradiation on T. gondii oocysts has been reported (Dubey et al., 1998c; Dubey et al., 1996; Dubey et al., 1998b). Viability was tested in mouse bioassays, with alpha-irradiation shown to be an effective means of killing $T$. gondii oocysts. Mice inoculated with gamma irradiated oocysts at 0.20 and $0.40 \mathrm{kGy}$ were partially protected when challenged orally with lethal doses of non-irradiated oocysts (Dubey et al., 1996). The effect of 137 Cs gamma irradiation was also investigated on unsporulated and sporulated oocysts in a model system for sterilization of fruit contaminated with other coccidia such as Cyclospora or Cryptosporidium. Unsporulated oocysts irradiated at $\geq 0.4$ to $0.8 \mathrm{kGy}$ were able to sporulate but were not infective to mice. Sporulated oocysts irradiated at $\geq 0.4 \mathrm{kGy}$ were able to excyst, and sporozoites were infective but not capable of establishing a continued infection in mice. Parasites were detected in histologic sections of mice for up to 5 days but not at 7 days after feeding oocysts irradiated at $0.5 \mathrm{kGy}$. Raspberries inoculated with sporulated $T$. gondii oocysts became innocuous after irradiation at $0.4 \mathrm{kGy}$ suggesting that irradiation at $0.5 \mathrm{kGy}$ may inactivate $T$. gondii oocysts on fruits and vegetables (Dubey et al., 1998c). In conclusion, these results should be interpreted with caution, as the ability of the parasite to infect mouse tissues, even if limited in duration during these experiments, may still have serious health repercussions in humans.

Experiments evaluating the efficacy of UV radiation - 
pulsed (PUV) and continuous (CUV) treatments - to inactivate $T$. gondii oocysts in water have yielded inconsistent results (Wainwright et al., 2007a; Dumetre et al., 2008; Ware et al., 2010). In these studies, sporulated oocysts were exposed to different UV radiation levels by varying the exposure time ranging from $20 \mathrm{~mJ} / \mathrm{cm} 2$ to 1,000 $\mathrm{mJ} / \mathrm{cm} 2$. Oocyst inactivation occurred at PUV doses as low as $40 \mathrm{~mJ} / \mathrm{cm} 2$ and CUV doses as low as $45 \mathrm{~mJ} / \mathrm{cm} 2$. However, oocyst inactivation was not $100 \%$ reliable at higher doses of UV administered both by pulsed and continuous sources. The study concluded with the recommendation that a minimum UV exposure dose of $1,000 \mathrm{~mJ} / \mathrm{cm} 2$ might be required for either PUV or CUV treatment of water to increase the probability of consistent and complete oocyst inactivation and indicated that further investigations of UV treatment to inactivate $T$. gondii oocysts should evaluate the effectiveness of UV radiation in water with different levels of turbidity (Wainwright et al., 2007a).
In contrast to the results reported by Wainwright et al., Dumetre et al. (2008) reported a $4 \log _{10}$ inactivation of $T$. gondii oocyst infectivity at UV exposure of $20 \mathrm{~mJ} / \mathrm{cm} 2$. Complementary studies of $\log _{10}$ inactivation were reported (Ware et al., 2010) with UV exposure ranging from 4 $\mathrm{mJ} / \mathrm{cm} 2$ to $100 \mathrm{~mJ} / \mathrm{cm} 2$. UV-irradiated oocyst disinfection was evaluated by three assays: a mouse bioassay, an in vitro T. gondii oocyst plaque (TOP) assay, and a quantitative reverse transcriptase real-time PCR (RT-qPCR) assay. Animal bioassays showed that 1 and $3 \log _{10}$ inactivation was achieved with $4 \mathrm{~mJ} / \mathrm{cm} 2 \mathrm{UV}$ and $10 \mathrm{~mJ} / \mathrm{cm} 2$ low-pressure UV, respectively. Authors concluded that 3 $\log _{10}$ inactivation is achievable at a $10-\mathrm{mJ} / \mathrm{cm} 2 \mathrm{UV}$ dose, and that it is applicable to the water industry. Because environmental samples have not been evaluated, studies are necessary to determine the specific UV dosage in drinking water and wastewater systems to render T. gondii noninfectious (Ware et al., 2010). 


\section{References}

Adl, S.M., Simpson, A.G., Lane, C.E., Lukeš, J., Bass, D., Bowser, S.S. et al. (2012). The revised classification of eukaryotes. Journal of Eukaryotic Microbiology. 59, pp. 429-493.

Adou-Bryn, K.D., Ouhon, J., Nemer, J., Yapo, C.G. and Assoumou, A. (2004). Serological survey of acquired toxoplasmosis in women of child-bearing age in Yopougon (Abidjan, Côte d'Ivoire). Bulletin de la Société de Pathologie Exotique. 97, pp. 345-348.

Afonso, E., Thulliez, P. and Gilot-Fromont, E. (2010). Local meteorological conditions, dynamics of seroconversion to Toxoplasma gondii in cats (Felis catus) and oocyst burden in a rural environment. Epidemiology and Infection. 138, pp. 1105-1113.

Aksoy, U., Marangi, M., Papini, R., Ozkoc, S., S Delibas, B. and Giangaspero, A. (2014). Detection of Toxoplasma gondii and Cyclospora cayetanensis in Mytilus galloprovincialis from Izmir Province coast (Turkey) by real time PCR/high resolution melting analysis (HRM). Food Microbiology. 44, pp. 128-135.

Aksoy, U., Marangi, M., Papini, R., Ozkoc, S., S Delibas, B. and Giangaspero, A. (2014). Detection of Toxoplasma gondii and Cyclospora cayetanensis in Mytilus galloprovincialis from Izmir province coast (Turkey) by real time PCR/High-Resolution Melting analysis (HRM). International Journal of Food Microbiology. 44, pp. 128-135.

Al-Megrin, W.A. (2010). Prevalence of Intestinal Parasites in Leafy Vegetables in Riyadh, Saudi Arabia. International Journal of Zoological Research. 6, pp. 190-195.

Alvarez, C., De-la-Torre, A., Vargas, M., Herrera, C., Uribe-Huertas, L.D., Lora, F. et al. (2015). Striking Divergence in Toxoplasma ROP16 Nucleotide Sequences From Human and Meat Samples. Journal of Infectious Diseases. 211, pp. 2006-2013.

Anand, R., Jones, C.W., Ricks, J.H., Sofarelli, T.A. and Hale, D.C. (2012). Acute primary toxoplasmosis in travelers returning from endemic countries. Journal of Travel Medicine. 19, pp. 57-60.

Arantes, T.E., Silveira, C., Holland, G.N., Muccioli, C., Yu, F., Jones, J.L. et al. (2015). Ocular Involvement Following Postnatally Acquired Toxoplasma gondii Infection in Southern Brazil: A 28-Year Experience. American Journal of Ophthalmology. 159, pp. 1002-1012.

Arkush, K.D., Miller, M.A., Leutenegger, C.M., Gardner, I.A., Packham, A.E., Heckeroth, A.R. et al. (2003). Molecular and bioassay-based detection of Toxoplasma gondii oocyst uptake by mussels (Mytilus galloprovincialis). International Journal for Parasitology. 33, pp. 1087-1097.

Aubert, D. and Villena, I. (2009). Detection of Toxoplasma gondii oocysts in water: proposition of a strategy and evaluation in Champagne-Ardenne Region, France. Memorias do Instituto Oswaldo Cruz. 104, pp. 290-295.

Bahia-Oliveira, L.M., Silva, J.A., Peixoto-Rangel, A.L., Boechat, M.S., Oliveira, A.M., Massara, C.L. et al. (2009). Host immune response to Toxoplasma gondii and Ascaris lumbricoides in a highly endemic area: evidence of parasite coimmunomodulation properties influencing the outcome of both infections. Memorias do Instituto Oswaldo Cruz. 104, pp. 273-280.

Bahia-Oliveira, L.M.G., Jones, J.L., Azevedo-Silva, J., Alves, C.C.F., Orefice, F. and Addiss, D.G. (2003). Highly endemic, waterborne toxoplasmosis in north Rio de Janeiro state, Brazil. Emerging Infectious Diseases. 9, pp. 55-62.

Batz, M.B., Hoffmann, S. and Morris, Jr, J.G. (2012). Ranking the disease burden of 14 pathogens in food sources in the United States using attribution data from outbreak investigations and expert elicitation. Journal of Food Protection. 75, pp. 1278-1291.

Besteiro, S., Michelin, A., Poncet, J., Dubremetz, J.F. and Lebrun, M. (2009). Export of a Toxoplasma gondii rhoptry neck protein complex at the host cell membrane to form the moving junction during invasion. PLoS Pathogens. 5, pp. e1000309. 
Bierly, A.L., Shufesky, W.J., Sukhumavasi, W., Morelli, A.E. and Denkers, E.Y. (2008). Dendritic cells expressing plasmacytoid marker PDCA-1 are Trojan horses during Toxoplasma gondii infection. Journal of Immunology. 181, pp. 8586-8491.

Boothroyd, J.C. and Dubremetz, J.F. (2008). Kiss and spit: the dual roles of Toxoplasma rhoptries. Nature Reviews. 6, pp. 79-88.

Boothroyd, J.C., Hehl, A., Knoll, L.J. and Manger, I.D. (1998). The surface of Toxoplasma: more and less. International Journal for Parasitology. 28, pp. 3-9.

Borchardt, M.A., Spencer, S.K., Bertz, P.D., Ware, M.W., Dubey, J.P. and Lindquist, HD.Alan (2009). Concentrating Toxoplasma gondii and Cyclospora cayetanensis from surface water and drinking water by continuous separation channel centrifugation. Journal of Applied Microbiology. 107, pp. 1089-1097.

Boughattas, S. (2015). Commentary on: "Detection of Toxoplasma gondii in raw caprine, ovine, buffalo, bovine, and camel milk using cell cultivation, cat bioassay, capture ELISA, and PCR methods in Iran". Frontiers in Microbiology. 6, pp. 215.

Bouratbine, A. and Aoun, K. (2014). Toxoplasmosis in the Middle East and North Africa. Neglected Tropical DiseasesMiddle East and North Africa. Springer. Vienna. pp. 235-249.

Bowie, W.R., King, A.S., Werker, D.H., IsaacRenton, J.L., Bell, A., Eng, S.B. et al. (1997). Outbreak of toxoplasmosis associated with municipal drinking water. Lancet. 350, pp. 173-177.

Bowman, D.D. and Fayer, R. (2005). Contemporary perspectives on infectious disease agents in sewage sludge and manure. Concerns related to protozoan and helminth parasites in biosolids and animal wastes. The JG Press, Inc. Emmaus, PA.

Boyer, K., Hill, D., Mui, E., Wroblewski, K., Karrison, T., Dubey, J.P. et al. (2011). Unrecognized ingestion of Toxoplasma gondii oocysts leads to congenital toxoplasmosis and causes epidemics in North America. Clinical Infectious Diseases. 53, pp. 1081-1089.

Butcher, B.A., Reese, M.L., Boothroyd, J.C. and Denkers, E.Y. (2014). Chapter 14 - Interactions Between Toxoplasma Effectors and Host Immune Responses. Toxoplasma gondii. Second Edi ed. Academic Press. Boston. pp. 505-519.

Buxton, D. and Innes, E.A. (1995). A commercial vaccine for ovine toxoplasmosis. Parasitology. 110, pp. S11-16.

Cérède, O., Dubremetz, J.F., Soête, M., Deslée, D., Vial, H., Bout, D. et al. (2005). Synergistic role of micronemal proteins in Toxoplasma gondii virulence. Journal of Experimental Medicine. 201, pp. 453-463.

Campos, F.A., Andrade, G.M., Lanna, A.P., Lage, B.F., Assumpção, M.V. and Pinto, J.A. (2014). Incidence of congenital toxoplasmosis among infants born to HIV-coinfected mothers: case series and literature review. Brazilian Journal of Infectious Diseases. 18, pp. 609-617.

Capobiango, J.D., Mitsuka-Breganó, R., Monica, T.C., Ferreira, F.P. and Reiche, E.M. (2015). Acute toxoplasmosis in a breastfed infant with possible transmission by water. Revista do Instituto de Medicina Tropical de São Paulo. 57, pp. 523-526.

Cardona, N.I., Moncada, D.M. and Gómez-Marín, J.E. (2015). A rational approach to select immunogenic peptides that induce IFN-\$gamma\$ response against Toxoplasma gondii in human leukocytes. Immunobiology. 220, pp. 1337-1342.

Carrington, E.G. (2001). Evaluation of Sludge treatments for pathogen reduction - Final Report. European Union. Luxembourg.

Carruthers, V. and Boothroyd, J.C. (2007). Pulling together: an integrated model of Toxoplasma cell invasion. Current opinion in Microbiology. 10, pp. 83-89.

Carruthers, V.B., Giddings, O.K. and Sibley, L.D. (1999). Secretion of micronemal proteins is associated with toxoplasma invasion of host cells. Cellular Microbiology. 1, pp. 225-235. 
Cañón-Franco, W.A., López-Orozco, N., Gómez-Marín, J.E. and Dubey, J.P. (2014). An overview of seventy years of research (1944-2014) on toxoplasmosis in Colombia, South America. Parasites and Vectors. 7, pp. 427.

Chatterton, J.M.W. (1992). Pregnancy. Human Toxoplasmosis. (Ho-Yen, D.O. and Joss, A.W., ed.). Oxford University Press. pp. 144-183.

Chessum, B.S. (1972). Reactivation of Toxoplasma oocyst production in the cat by infection with Isospora felis. British Veterinary Journal. 128, pp. 33-36.

Chtanova, T., Schaeffer, M., Han, S.J., van Dooren, G.G., Nollmann, M., Herzmark, P. et al. (2008). Dynamics of neutrophil migration in lymph nodes during infection. Immunity. 29, pp. 487-496.

Cong, H., Mui, E.J., Witola, W.H., Sidney, J., Alexander, J., Sette, A. et al. (2012). Toxoplasma gondii HLA-B*0702-restricted GRA7(20-28) peptide with adjuvants and a universal helper T cell epitope elicits CD8(+) T cells producing interferon\$lgamma\$ and reduces parasite burden in HLA-B*0702 mice. Human Immunology. 73, pp. 1-10.

Cortina-Borja, M., Tan, H.K., Wallon, M., Paul, M., Prusa, A., Buffolano, W. et al. (2010). Prenatal treatment for serious neurological sequelae of congenital toxoplasmosis: an observational prospective cohort study. PLoS Medicine. 7,.

Courret, N., Darche, S., Sonigo, P., Milon, G., Buzoni-Gâtel, D. and Tardieux, I. (2006). CD11c- and CD11b-expressing mouse leukocytes transport single Toxoplasma gondii tachyzoites to the brain. Blood. 107, pp. 309-316.

Coutinho, S.G., Lobo, R. and Dutra, G. (1982). Isolation of Toxoplasma from the soil during an outbreak of Toxoplasmosis in a rural area in Brazil. Journal of Parasitology. 68, pp. 866-868.

Dabritz, H.A. and Conrad, P.A. (2010). Cats and Toxoplasma: implications for public health. Zoonoses and Public Health. 57, pp. 34-52.

Dabritz, H.A., Miller, M.A., Atwill, E.R., Gardner, I.A., Leutenegger, C.M., Melli, A.C. et al. (2007). Detection of Toxoplasma gondii-like oocysts in cat feces and estimates of the environmental oocyst burden. Journal of the American Veterinary Medical Association. 231, pp. 1676-1684.

Daniels, M.E., Hogan, J., Smith, W.A., Oates, S.C., Miller, M.A., Hardin, D. et al. (2014). Estimating environmental conditions affecting protozoal pathogen removal in surface water wetland systems using a multi-scale, model-based approach. Science of the Total Environment. 493, pp. 1036-1046.

Dardé, M.L., Ajzenberg, D. and Su, C. (2014). Molecular epidemiology and population structure of Toxoplasma gondii. Toxoplasma gondii (Second Edition)-The Model Apicomplexan-Perspectives and Methods. pp. 61-67.

Dattoli, V.C., Veiga, R.V., Cunha, S.S., Pontes-de-Carvalho, L., Barreto, M.L. and Alcântara-Neves, N.M. (2011). Oocyst ingestion as an important transmission route of Toxoplasma gondii in Brazilian urban children. Journal of Parasitology. 97, pp. 1080-1084.

De-la-Torre, A., González-López, G., Montoya-Gutiérrez, J.M., Marín-Arango, V. and Gómez-Marín, J.E. (2011). Quality of life assessment in ocular toxoplasmosis in a Colombian population. Ocular Immunology and Inflammation. 19, pp. 262-266.

De-la-Torre, A., López-Castillo, C.A. and Gómez-Marín, J.E. (2009). Incidence and clinical characteristics in a Colombian cohort of ocular toxoplasmosis. Eye. 23, pp. 1090-1093.

De-la-Torre, A., López-Castillo, C.A., Rueda, J.C., Mantilla, R.D., Gómez-Marín, J.E. and Anaya, J.M. (2009). Clinical patterns of uveitis in two ophthalmology centres in Bogota, Colombia. Clinical and Experimental Ophthalmology. 37, pp. 458-466.

De-la-Torre, A., Sauer, A., Pfaff, A.W., Bourcier, T., Brunet, J., Speeg-Schatz, C. et al. (2013). Severe South American ocular toxoplasmosis is associated with decreased Ifn-\$gamma\$/Il-17a and increased Il-6/Il-13 intraocular levels. PLOS Neglected Tropical Diseases. 7, pp. e2541.

Demirel, E., Koloren, Z., Karaman, U. and Ayaz, E. (2014). Investigation on Toxoplasma gondii by polymerase chain reaction and loop-mediated isothermal amplification in water samples from Giresun, Turkey. Mikrobiyoloji Bülteni. 48, pp. 
661-668.

de Moura, L., Bahia-Oliveira, L.M.G., Wada, M.Y., Jones, J.L., Tuboi, S.H., Carmo, E.H. et al. (2006). Waterborne toxoplasmosis, Brazil, from field to gene. Emerging Infectious Diseases. 12, pp. 326-329.

Derouin, F., Pelloux, H. and,. (2008). Prevention of toxoplasmosis in transplant patients. Clinical Microbiology and Infection. 14, pp. 1089-1101.

Desmonts, G., Couvreur, J., Alison, F., Baudelot, J., Gerbeaux, J. and Lelong, M. (1965). Epidemiological study on toxoplasmosis: the influence of cooking slaughter-animal meat on the incidence of human infection. Revue europeenne d'etude clinique et biologique. 10, pp. 952-958.

de Souza, W. (1972). Mise en évidence et structure du système microtubulaire de Toxoplasma gondii. Comptes rendus hebdomadaires des séances de l'Académie des sciencesSérie D: Sciences naturelles. 275, pp. 2899-2901.

de Souza, W. and Souto-Padrón, T. (1978). Ultrastructural localization of basic proteins on the conoid, rhoptries and micronemes of Toxoplasma gondii. Z Parasitenkd. 56, pp. 123-129.

Dickerson, F.B., Stallings, C.R., Boronow, J.J., Origoni, A.E. and Yolken, R.H. (2009). A double-blind trial of adjunctive azithromycin in individuals with schizophrenia who are seropositive for Toxoplasma gondii. Schizophrenia Research. 112, pp. 198-199.

Di Mario, S., Basevi, V., Gagliotti, C., Spettoli, D., Gori, G., D'Amico, R. et al. (2015). Prenatal education for congenital toxoplasmosis. Cochrane database of systematic reviews. 10, pp. CD006171.

Domingos, A., Ito, L.S., Coelho, E., Lúcio, J.M., Matida, L.H. and Jr, AN.Ramos (2013). Seroprevalence of Toxoplasma gondii IgG antibody in HIV/AIDS-infected individuals in Maputo, Mozambique. Revista de Saúde Pública. 47, pp. 890-896.

Dubey, J.K., Miller, N.L. and Frenkel, J.K. (1970). Characterization of the new fecal form of Toxoplasma gondii. Journal of Parasitology. 56, pp. 447-456.

Dubey, J.P. (2009). Toxoplasmosis of Animals and Humans. Second ed. CRC Press. London.

Dubey, J.P. (2006). Comparative infectivity of oocysts and bradyzoites of Toxoplasma gondii for intermediate (mice) and definitive (cats) hosts. Veterinary Parasitology. 140, pp. 69-75.

Dubey, J.P. (2001). Oocyst shedding by cats fed isolated bradyzoites and comparison of infectivity of bradyzoites of the VEG strain Toxoplasma gondii to cats and mice. Journal of Parasitology. 87, pp. 215-219.

Dubey, J.P. (1998). Toxoplasma gondii oocyst survival under defined temperatures. Journal of Parasitology. 84, pp. 862-865.

Dubey, J.P. (1998). Advances in the life cycle of Toxoplasma gondii. International Journal of Parasitology. 28, pp. 1019-1024.

Dubey, J.P. (1997). Tissue cyst tropism in Toxoplasma gondii: a comparison of tissue cyst formation in organs of cats, and rodents fed oocysts. Parasitology. 115, pp. 15-20.

Dubey, J.P. (1996). Infectivity and pathogenicity of Toxoplasma gondii oocysts for cats. Journal of Parasitology. 82, pp. 957-961.

Dubey, J.P. (1995). Duration of immunity to shedding of Toxoplasma gondii oocysts by cats. Journal of Parasitology. 81, pp. 410-415.

Dubey, J.P. (1976). Reshedding of Toxoplasma oocysts by chronically infected cats. Nature. 262, pp. 213-214.

Dubey, J.P. (2010). General Biology. Toxoplasmosis of Animals and Humans. Second ed. (Dubey, J.P., ed.). CRC Press. Boca Raton, FL. 
Dubey, J.P. and Frenkel, J.K. (1976). Feline toxoplasmosis from acutely infected mice and the development of Toxoplasma cysts. Journal of Protozoology. 23, pp. 537-546.

Dubey, J.P. and Frenkel, J.K. (1974). Immunity to feline toxoplasmosis: modification by administration of corticosteroids. Veterinary Pathology. 11, pp. 350-379.

Dubey, J.P., Jenkins, M.C., Thayer, D.W., Kwok, O.C. and Shen, S.K. (1996). Killing of Toxoplasma gondii oocysts by irradiation and protective immunity induced by vaccination with irradiated oocysts. Journal of Parasitology. 82, pp. 724-727.

Dubey, J.P., Lago, E.G., Gennari, S.M., Su, C. and Jones, J.L. (2012). Toxoplasmosis in humans and animals in Brazil: high prevalence, high burden of disease, and epidemiology. Parasitology. 139, pp. 1375-1424.

Dubey, J.P., Lunney, J.K., Shen, S.K. and Kwok, O.C. (1998). Immunity to toxoplasmosis in pigs fed irradiated Toxoplasma gondii oocysts. Journal of Parasitology. 84, pp. 749-752.

Dubey, J.P., Thayer, D.W., Speer, C.A. and Shen, S.K. (1998). Effect of gamma irradiation on unsporulated and sporulated Toxoplasma gondii oocysts. International Journal of Parasitology. 28, pp. 369-375.

Dumètre, A. and Dardé, M.L. (2007). Detection of Toxoplasma gondii in water by an immunomagnetic separation method targeting the sporocysts. Parasitology Research. 101, pp. 989-996.

Dumètre, A. and Dardé, M.L. (2005). Immunomagnetic separation of Toxoplasma gondii oocysts using a monoclonal antibody directed against the oocyst wall. Journal of Microbiological Methods. 61, pp. 209-217.

Dumètre, A. and Dardé, M.L. (2003). How to detect Toxoplasma gondii oocysts in environmental samples?. FEMS Microbiology Reviews. 27, pp. 651-661.

Dumètre, A., Le Bras, C., Baffet, M., Meneceur, P., Dubey, J.P., Derouin, F. et al. (2008). Effects of ozone and ultraviolet radiation treatments on the infectivity of Toxoplasma gondii oocysts. Veterinary Parasitology. 153, pp. 209-213.

Dutra, M.S., Bela, S.R., Peixoto-Rangel, A.L., Fakiola, M., Cruz, A.G., Gazzinelli, A. et al. (2013). Association of a NOD2 gene polymorphism and T-helper 17 cells with presumed ocular toxoplasmosis. The Journal of Infectious Diseases. 207, pp. 152-163.

Elbez-Rubinstein, A., Ajzenberg, D., Dardé, M.L., Cohen, R., Dumètre, A., Yera, H. et al. (2009). Congenital toxoplasmosis and reinfection during pregnancy: case report. The Journal of Infectious Diseases. 199, pp. 280-285.

Elsheikha, H.M., Büsselberg, D. and Zhu, X.Q. (2016). The known and missing links between Toxoplasma gondii and schizophrenia. Metabolic Brain Disease.

Esmerini, P.O., Gennari, S.M. and Pena, H.F.J. (2010). Analysis of marine bivalve shellfish from the fish market in Santos city, Sao Paulo state, Brazil, for Toxoplasma gondii. Veterinary Parasitology. 179, pp. 8-13.

Ferguson, D.J. and Hutchinson, W.M. (1987). The host-parasite relationship of Toxoplasma gondii in the brains of chronically infected mice. Virchows Archiv: European Journal of Pathology. 411, pp. 39-43.

Ferguson, D.J. and Hutchison, W.M. (1987). An ultrastructural study of the early development and tissue cyst formation of Toxoplasma gondii in the brains of mice. Parasitology Research. 73, pp. 483-491.

Ferguson, D.J.P. (2009). Toxoplasma gondii: 1908-2008, homage to Nicolle, Manceaux and Splendore. Memorias do Instituto Oswaldo Cruz. 104, pp. 132-147.

Finch, G.R., Black, E.K., Gyürék, L. and Belosevic, M. (1993). Ozone inactivation of Cryptosporidium parvum in demandfree phosphate buffer determined by in vitro excystation and animal infectivity. Applied and Environmental Microbiology. 59, pp. 4203-4210.

Flegr, J. and Hrdý, I. (1994). Influence of chronic toxoplasmosis on some human personality factors. Folia Parasitologica. 
41, pp. 122-126.

Fond, G., Boyer, L., Gaman, A., Laouamri, H., Attiba, D.,.. et al. (2015). Treatment with anti-toxoplasmic activity (TATA) for toxoplasma positive patients with bipolar disorders or schizophrenia: a cross-sectional study. Journal of Psychiatric Research. 63, pp. 58-64.

Foroutan-Rad, M., Majidiani, H., Dalvand, S., Daryani, A., Kooti, W., Saki, J. et al. (2016). Toxoplasmosis in Blood Donors: A Systematic Review and Meta-Analysis. Transfusion Medicine Reviews.

Franco, P.S., da Silva, N.M., B Barbosa, de.Freitas, A Gomes, de.Oliveira, Ietta, F., Shwab, E.K. et al. (2015). Calomys callosus chronically infected by Toxoplasma gondii clonal type II strain and reinfected by Brazilian strains is not able to prevent vertical transmission. Frontiers in Microbiology. 6, pp. 181.

Frenkel, J.K. (1973). Toxoplasma in and around. BioScience. 23, pp. 343-352.

Frenkel, J.K. and Dubey, J.P. (1973). Effects of freezing on viability of Toxoplasma oocysts. Journal of Parasitology. 59, pp. 587-588.

Frenkel, J.K. and Dubey, J.P. (1972). Toxoplasmosis and its prevention in cats and man. The Journal of Infectious Diseases. 126, pp. 664-673.

Frenkel, J.K., Hassanein, K.M., Hassanein, R.S., Brown, E., Thulliez, P. and Quinteronunez, R. (1995). Transmission of Toxoplasma gondii in Panama City, Panama - A 5-year prospective cohort study of children, cats, rodents, birds and soi. The American Journal of Tropical Medicine and Hygiene. 53, pp. 458-468.

Frenkel, J.K. and Ruiz, A. (1981). Endemicity of toxoplasmosis in Costa Rica. American Journal of Epidemiology. 113, pp. 254-269.

Frenkel, J.K., Ruiz, A. and Chinchilla, M. (1975). Soil survival of Toxoplasma oocysts in Kansas and Costa-Rica. The American Journal of Tropical Medicine and Hygiene. 24, pp. 439-443.

Freyre, A., Dubey, J.P., Smith, D.D. and Frenkel, J.K. (1989). Oocyst-induced Toxoplasma gondii infections in cats. Journal of Parasitology. 75, pp. 750-755.

Fromont, E.G., Riche, B. and Rabilloud, M. (2009). Toxoplasma seroprevalence in a rural population in France: detection of a household effect. BMC Infectious Diseases. 9, pp. 76.

Gómez-Marín, J.E., De-la-Torre, A., Angel-Muller, E., Rubio, J., Arenas, J., Osorio, E. et al. (2011). First Colombian multicentric newborn screening for congenital toxoplasmosis. PLOS Neglected Tropical Diseases. 5, pp. e1195.

Gallas-Lindemann, C., Sotiriadou, I., Mahmoodi, M.R. and Karanis, P. (2013). Detection of Toxoplasma gondii oocysts in different water resources by Loop Mediated Isothermal Amplification (LAMP). Acta Tropica. 125, pp. 231-236.

Gavinet, M.F., Robert, F., Firtion, G., Delouvrier, E., Hennequin, C.,.. et al. (1997). Congenital toxoplasmosis due to maternal reinfection during pregnancy. Journal of Clinical Microbiology. 35, pp. 1276-1277.

Gomez-Marín, J., Alvarado, F., Hernández, C., Cuervo, S. and Saraiva, J. (2001). Tratamiento de la fase aguda de la toxoplasmosis cerebral con clindamicina - falcidar (pirimetamina - sulfadoxina) en pacientes infectados por VIH. Infectio. 5, pp. 163-169.

Gotteland, C., Gilot-Fromont, E., Aubert, D., Poulle, M.L., Dupuis, E., Dardé, M.L. et al. (2014). Spatial distribution of Toxoplasma gondii oocysts in soil in a rural area: Influence of cats and land use. Veterinary Parasitology. 205, pp. 629-637.

Haakansson, S., Charron, A.J. and Sibley, L.D. (2001). Toxoplasma evacuoles: a two-step process of secretion and fusion forms the parasitophorous vacuole. EMBOJ. 20, pp. 3132-3144.

Hald, T., Aspinall, W., Devleesschauwer, B., Cooke, R., Corrigan, T., Havelaar, A.H. et al. (2016). World Health Organization Estimates of the Relative Contributions of Food to the Burden of Disease Due to Selected Foodborne Hazards: 
A Structured Expert Elicitation. PLoS ONE. 11, pp. e0145839.

Havelaar, A.H., Haagsma, J.A., Mangen, M.J., Kemmeren, J.M., Verhoef, L.P., Vijgen, S.M. et al. (2012). Disease burden of foodborne pathogens in the Netherlands, 2009. International Journal of Food Microbiology. 156, pp. 231-238.

Henriquez, F.L., Woods, S., Cong, H., McLeod, R. and Roberts, C.W. (2010). Immunogenetics of Toxoplasma gondii informs vaccine design. Trends in Parasitology. 26, pp. 550-555.

Herwaldt, B.L. (2001). Laboratory-acquired parasitic infections from accidental exposures. Clinical Microbiology Reviews. 14, pp. 659-688.

Hill, D., Coss, C., Dubey, J.P., Wroblewski, K., Sautter, M., Hosten, T. et al. (2011). Identification of a sporozoite-specific antigen from Toxoplasma gondii. Journal of Parasitology. 97, pp. 328-337.

Hofhuis, A., Van Pelt, W., van Duynhoven, Y.T., Nijhuis, C.D., Mollema, L., van der Klis, F.R. et al. (2011). Decreased prevalence and age-specific risk factors for Toxoplasma gondii IgG antibodies in The Netherlands between 1995/1996 and 2006/2007. Epidemiology and Infection. 139, pp. 530-538.

Hogan, J.N., Daniels, M.E., Watson, F.G., Oates, S.C., Miller, M.A., Conrad, P.A. et al. (2013). Hydrologic and Vegetative Removal of Cryptosporidium parvum, Giardia lamblia, and Toxoplasma gondii Surrogate Microspheres in Coastal Wetlands. Applied and Environmental Microbiology. 79, pp. 1859-1865.

Hohweyer, J., Cazeaux, C., Travaillé, E., Languet, E., Dumètre, A., Aubert, D. et al. (2016). Simultaneous detection of the protozoan parasites Toxoplasma, Cryptosporidium and Giardia in food matrices and their persistence on basil leaves. Food Microbiology. 57, pp. 36-44.

Holland, G.N. (2009). Ocular toxoplasmosis: the influence of patient age. Memorias do Instituto Oswaldo Cruz. 104, pp. 351-357.

Holland, G.N. (2003). LX Edward Jackson memorial lecture - Ocular toxoplasmosis: A global reassessment. Part 1: Epidemiology and course of disease. American Journal of Ophthalmology. 136, pp. 973-988.

Horacek, J., Flegr, J., Tintera, J., Verebova, K., Spaniel, F., Novak, T. et al. (2012). Latent toxoplasmosis reduces gray matter density in schizophrenia but not in controls: voxel-based-morphometry (VBM) study. World Journal of Biological Psychiatry. 13, pp. 501-509.

Hotop, A., Hlobil, H. and Gross, U. (2012). Efficacy of rapid treatment initiation following primary Toxoplasma gondii infection during pregnancy. Clinical Infectious Diseases. 54, pp. 1545-1552.

Howe, D.K. and Sibley, L.D. (1995). Toxoplasma gondii comprises 3 clonal lineages - correlatin of parasite genotype with human. The Journal of Infectious Diseases. 172, pp. 1561-1566.

Hughes, J.M., Colley, D.G., Lopez, A., Dietz, V.J., Wilson, M., Navin, T.R. et al. (2000). Preventing Congenital Toxoplasmosis. Morbidity and Mortality Weekly Report: Recommendations and Reports. 49, pp. 57-75.

Hunter, C.A. and Sibley, L.D. (2012). Modulation of innate immunity by Toxoplasma gondii virulence effectors. Nature Reviews Microbiology. 10, pp. 766-778.

Isaac-Renton, J., Bowie, W.R., King, A., Irwin, G.S., Ong, C.S., Fung, C.P. et al. (1998). Detection of Toxoplasma gondii oocysts in drinking water. Applied and Environmental Microbiology. 64, pp. 2278-2280.

Ito, S., Tsunoda, K., Tsutsumi, Y., Matsui, T., Nishikawa, H., Iida, T. et al. (1975). Detection and confirmation of Toxoplasma oocysts in soil. Japanese journal of Veterinary Science. 37, pp. 549-554.

Jackson, M.H. and Hutchinson, W.M. (1989). The prevalence and source of Toxoplasma infection in the environment. Advances in Parasitology. 28, pp. 55-105.

Jacobs, L. (1957). The interrelation of toxoplasmosis in swine, cattle, dogs, and man. Public Health Reports. 72, pp. 
827-882.

Jacobs, L. and Melton, M.L. (1966). Toxoplasmosis in chickens. Journal of Parasitology. 52, pp. 1158-1162.

Janse, J.J., Wong, G.W., Potts, J., Ogorodova, L.M., Fedorova, O.S., Mahesh, P.A. et al. (2014). The association between foodborne and orofecal pathogens and allergic sensitisation - EuroPrevall study. Pediatric Allergy and Immunology. 25, pp. 250-256.

John, L.N., McBride, W.J., Millan, J. and Wilson, K. (2012). Seroprevalence of anti-Toxoplasma gondii antibodies in HIV/AIDS patients and healthy blood donors at the Port Moresby General Hospital, Papua New Guinea. Papua New Guinea Medical Journal. 55, pp. 88-93.

Johnson, C.K., Tinker, M.T., Estes, J.A., Conrad, P.A., Staedler, M., Miller, M.A. et al. (2009). Prey choice and habitat use drive sea otter pathogen exposure in a resource-limited coastal system. Proceedings of the National Academy of Sciences of the United States of America. 106, pp. 2242-2247.

Jones, J.L., Bonetti, V., Holland, G.N., Press, C.,,., Khurana, R.N. et al. (2015). Ocular toxoplasmosis in the United States: recent and remote infections. Clinical Infectious Diseases. 60, pp. 271-273.

Jones, J.L., Dargelas, V., Roberts, J., Press, C., Remington, J.S. and Montoya, J.G. (2009). Risk factors for Toxoplasma gondii infection in the United States. Clinical Infectious Diseases. 49, pp. 878-884.

Jones, J.L. and Dubey, J.P. (2012). Foodborne toxoplasmosis. Clinical Infectious Diseases. 55, pp. 845-851.

Jones, J.L. and Dubey, J.P. (2010). Waterborne toxoplasmosis-recent developments. Experimental Parasitology. 124, pp. 10-25.

Jones, J.L., Kruszon-Moran, D., Sanders-Lewis, K. and Wilson, M. (2007). Toxoplasma gondii infection in the United States, 1999 2004, decline from the prior decade. The American Journal of Tropical Medicine and Hygiene. 77, pp. 405-410.

Jones, J.L., Ogunmodede, F., Scheftel, J., Kirkland, E., Lopez, A., Schulkin, J. et al. (2003). Toxoplasmosis-related knowledge and practices among pregnant women in the United States. Infectious Diseases in Obstetrics and Gynecology. 11, pp. 139-145.

Jones, J.L., Parise, M.E. and Fiore, A.E. (2014). Neglected parasitic infections in the United States: toxoplasmosis. The American Journal of Tropical Medicine and Hygiene. 90, pp. 794-799.

Jongert, E., Roberts, C.W., Gargano, N., Förster-Waldl, E., Förster-Wald, E. and Petersen, E. (2009). Vaccines against Toxoplasma gondii: challenges and opportunities. Memórias do Instituto Oswaldo Cruz. 104, pp. 252-266.

Karanis, P., Aldeyarbi, H.M., Mirhashemi, M.E. and Khalil, K.M. (2013). The impact of the waterborne transmission of Toxoplasma gondii and analysis efforts for water detection: an overview and update. Environmental Science and Pollution Research International. 20, pp. 86-99.

Kerambrun, E., Ladeiro, M.P., Bigot-Clivot, A., Dedourge-Geffard, O., Dupuis, E., Villena, I. et al. (2016). Zebra mussel as a new tool to show evidence of freshwater contamination by waterborne Toxoplasma gondii. Journal of Applied Microbiology. 120, pp. 498-508.

Khan, A., Dubey, J.P., Su, C., Ajioka, J.W., Rosenthal, B.M. and Sibley, L.D. (2011). Genetic analyses of atypical Toxoplasma gondii strains reveal a fourth clonal lineage in North America. International Journal of Parasitology. 41, pp. 645-655.

Khan, A., Taylor, S., Su, C., Sibley, L.D., Paulsen, I. and Ajioka, J.W. (2007). Genetics and Genomic Organization of Toxoplasma gondii. Toxoplasma: Molecular and Cellular Biology. (Ajioka, J.W. and Soldati, D., ed.). Horizon Bioscience. Whymondham, UK. pp. 626.

Khan, I., Khan, A.M., Ayaz, S., Khan, S., Anees, M., Khan, S.A. et al. (2013). Molecular detection of Toxoplasma gondii in water soruces of district Nowshehra Khyber Pakhtunhwa, Pakistan. Journal of Toxicology and Environmental Health-Part aCurrent Issues. 76, pp. 837-841. 
Kieffer, F., Wallon, M., Garcia, P., Thulliez, P., Peyron, F. and Franck, J. (2008). Risk factors for retinochoroiditis during the first 2 years of life in infants with treated congenital toxoplasmosis. The Pediatric Infectious Disease Journal. 27, pp. 27-32.

Kijlstra, A. and Jongert, E. (2009). 'Toxoplasma-safe meat: close to reality?. Trends in Parasitology. 25, pp. 18-22.

Kijlstra, A. and Peterson, E. (2014). Epidemiology, Pathophysiology, and the Future of Ocular Toxoplasmosis. Ocular Immunology and Inflammation. 22, pp. 138-147.

Kodjikian, L., Hoigne, I., Adam, O., Jacquier, P., Aebi-Ochsner, C., Aebi, C. et al. (2004). Vertical transmission of toxoplasmosis from a chronically infected immunocompetent woman. The Pediatric Infectious Disease Journal. 23, pp. 272-274.

Koloren, Z. and Demirel, E. (2013). Detection of Toxoplasma gondii in Turkish River and Drinking Water Samples by Different PCR and LAMP Methods. Clean-Soil Air Water. 41, pp. 963-968.

Kourenti, C., Heckeroth, A., Tenter, A. and Karanis, P. (2003). Development and application of different methods for the detection of Toxoplasma gondii in water. Applied and Environmental Microbiology. 69, pp. 102-106.

Kourenti, C. and Karanis, P. (2006). Evaluation and applicability of a purification method coupled with nested PCR for the detection of Toxoplasma oocysts in water. Letters in Applied Microbiology. 43, pp. 475-481.

Kourenti, C. and Karanis, P. (2004). Development of a sensitive polymerase chain reaction method for the detection of Toxoplasma gondii in water. Water Science and Technology. 50, pp. 287-291.

Krusor, C., Smith, W.A., Tinker, M.T., Silver, M., Conrad, P.A. and Shapiro, K. (2015). Concentration and retention of Toxoplasma gondii oocysts by marine snails demonstrate a novel mechanism for transmission of terrestrial zoonotic pathogens in coastal ecosystems. Environmental Microbiology.

Kur, J., Holec-Gasior, L. and Hiszczyńska-Sawicka, E. (2009). Current status of toxoplasmosis vaccine development. Expert Review of Vaccines. 8, pp. 791-808.

López-Castillo, C.A., Díaz-Ramirez, J. and Gómez-Marín, J.E. (2005). Risk factors for Toxoplasma gondii infection in pregnant women in Armenia, Colombia. Revista Panamericana de Salud Pública. 7, pp. 180-190.

Ladas, I.D., Rallatos, C.L., Kanaki, C.S., Damanakis, A.G., Zafirakis, P.K. and Rallatos, G. (199). Presumed congenital ocular toxoplasmosis in two successive siblings. Opthalmologica. 213, pp. 320-322.

M Ladeiro, P., Aubert, D., Villena, I., Geffard, A. and Bigot, A. (2014). Bioaccumulation of human waterborne protozoa by zebra mussel (Dreissena polymorpha): interest for water biomonitoring. Water Research. 48, pp. 148-155.

Lass, A., Pietkiewicz, H., Modzelewska, E., Dumètre, A., Szostakowska, B. and Myjak, P. (2009). Detection of Toxoplasma gondii oocysts in environmental soil samples using molecular methods. European Journal of Clinical Microbiology and Infectious Diseases. 28, pp. 599-605.

Lass, A., Pietkiewicz, H., Szostakowska, B. and Myjak, P. (2012). The first detection of Toxoplasma gondii DNA in environmental fruits and vegetables samples. European Journal of Clinical Microbiology and Infectious Diseases. 31, pp. 1101-1108.

Lehmann, T., Marcet, P.L., Graham, D.H., Dahl, E.R. and Dubey, J.P. (2006). Globalization and the population structure of Toxoplasma gondii. Proceedings of the National Academy of Sciences of the United States of America. 103, pp. 11423-11428.

Lelu, M., Villena, I., Dardé, M.L., Aubert, D., Geers, R., Dupuis, E. et al. (2012). Quantitative Estimation of the Viability of Toxoplasma gondii Oocysts in Soil. Applied and Environmental Microbiology. 78, pp. 5127-5132.

Lilly, E.L. and Wortham, C.D. (2013). High prevalence of Toxoplasma gondii oocyst shedding in stray and pet cats (Felis catus) in Virginia, United States. Parasites and Vectors. 6, pp. 4. 
Lim, H., Lee, S.E., Jung, B.K., Kim, M.K., Lee, M.Y., Nam, H.W. et al. (2012). Serologic survey of toxoplasmosis in Seoul and Jeju-do, and a brief review of its seroprevalence in Korea. Korean Journal of Parasitology. 50, pp. 287-293.

Lindquist, H.D., Bennett, J.W., Hester, J.D., Ware, M.W., Dubey, J.P. and Everson, W.V. (2003). Autofluorescence of Toxoplasma gondii and related coccidian oocysts. Journal of Parasitology. 89, pp. 865-867.

Lindsay, D.S., Collins, M.V., Mitchell, S.M., Wetch, C.N., Rosypal, A.C., Flick, G.J. et al. (2004). Survival of Toxoplasma gondii oocysts Eastern oysters (Crassostrea virginica). Journal of Parasitology. 90, pp. 1054-1057.

Lindsay, D.S. and Dubey, J.P. (2009). Long-term survival of Toxoplasma gondii sporulated oocysts in seawater. Journal of Parasitology. 95, pp. 1019-1020.

Lindsay, D.S., Dubey, J.P., Butler, J.M. and Blagburn, B.L. (1997). Mechanical transmission of Toxoplasma gondii oocysts by dogs. Veterinary Parasitology. 73, pp. 27-33.

Lito, D., Francisco, T., Salva, I., Tavares, M., Oliveira, R. and Neto, M.T. (2013). TORCH serology and group B Streptococcus screening analysis in the population of a maternity. Acta Médica Portuguesa. 26, pp. 549-554.

Lora-Suarez, F., Rivera, R., Triviño-Valencia, J. and Gómez-Marín, J.E. (2016). Detection of protozoa in water samples by formalin/ether concentration method. Water Research. 100, pp. 377-381.

Lorenzi, H., Khan, A., Behnke, M.S., Namasivayam, S., Swapna, L.S., Hadjithomas, M. et al. (2016). Local admixture of amplified and diversified secreted pathogenesis determinants shapes mosaic Toxoplasma gondii genomes. Nature Communications. 7, pp. 10147.

Mahmoudi, M.R., Kazemi, B., Haghighi, A. and Karanis, P. (2015). Detection of Acanthamoeba and Toxoplasma in River Water Samples by Molecular Methods in Iran. Iranian Journal of Parasitology. 10, pp. 250-257.

Mai, K., Sharman, P.A., Walker, R.A., Katrib, M., Souza, D.D., McConville, M.J. et al. (2009). Oocyst wall formation and composition in coccidian parasites. Memórias do Instituto Oswaldo Cruz. 104, pp. 281-289.

Mangiavacchi, B.M., Vieira, F.P., Bahia-Oliveira, L.M. and Hill, D. (2016). Salivary IgA against sporozoite-specific embryogenesis-related protein (TgERP) in the study of horizontally transmitted toxoplasmosis via $T$. gondii oocysts in endemic settings. Epidemiology and Infection. pp. 1-10.

Marangi, M., Giangaspero, A., Lacasella, V., Lonigro, A. and Gasser, R.B. (2015). Multiplex PCR for the detection and quantification of zoonotic taxa of Giardia, Cryptosporidium and Toxoplasma in wastewater and mussels. Molecular and Cellular Probes. 29, pp. 122-125.

Marchiondo, A.A., Duszynski, D.W. and Maupin, G.O. (1976). Prevalence of antibodies to Toxoplasma gondii in wild and domestic animals of New Mexico, Arizona and Colorado. Journal of Wildlife Diseases. 12, pp. 226-232.

Martino, R., Bretagne, S., Rovira, M., Ullmann, A.J., Maertens, J., Held, T. et al. (2000). Toxoplasmosis after hematopoietic stem transplantation. Report of a 5-year survey from the Infectious Diseases Working Party of the European Group for Blood and Marrow Transplantation. Bone Marrow Transplant. 25, pp. 1111-1114.

Maschke, M., Dietrich, U., Prumbaum, M., Kastrup, O., Turowski, B., Schaefer, U.W. et al. (1999). Opportunistic CNS infection after bone marrow transplantation. Bone Marrow Transplant. 23, pp. 1167-1176.

Massie, G.N., Ware, M.W., Villegas, E.N. and Black, M.W. (2010). Uptake and transmission of Toxoplasma gondii oocysts by migratory, filter-feeding fish. Veterinary Parasitology. 169, pp. 296-303.

McLeod, R., Boyer, K., Karrison, T., Kasza, K., Swisher, C., Roizen, N. et al. (2006). Outcome of Treatment for Congenital Toxoplasmosis, 1981-2004: The National Collaborative Chicago-Based, Congenital Toxoplasmosis Study. Clinical Infectious Diseases. 42, pp. 1383-1394.

McLeod, R., Kieffer, F., Sautter, M., Hosten, T. and Pelloux, H. (2009). Why prevent, diagnose and treat congenital toxoplasmosis?. Mem Inst Oswaldo Cruz. 104, pp. 320-344. 
Meerburg, B.G. and Kijlstra, A. (2009). Changing climate-changing pathogens: Toxoplasma gondii in North-Western Europe. Parasitology Research. 105, pp. 17-24.

Meireles, L.R., Ekman, C.C., jR, HF.Andrade and Luna, E.J. (2015). Human toxoplasmosis outbreaks and the agent infecting form. findings from a systematic review. Revista do Instituto de Medicina Tropical de São Paulo. 57, pp. 369-376.

Miller, M.A., Grigg, M.E., Kreuder, C., James, E.R., Melli, A.C., Crosbie, P.R. et al. (2004). An unusual genotype of Toxoplasma gondii is common in California sea otters (Enhydra lutris nereis) and is a cause of mortality. International Journal of Parasitology. 34, pp. 275-284.

Miller, M.A., Miller, W.A., Conrad, P.A., James, E.R., Melli, A.C., Leutenegger, C.M. et al. (2008). Type X Toxoplasma gondii in a wild mussel and terrestrial carnivores from coastal California: New linkages between terrestrial mammals, runoff and toxoplasmosis of sea otters. International Journal of Parasitology. 38, pp. 1319-1328.

Miller, M.J., Aronson, W.J. and Remington, J.S. (1969). Late parasitemia in asymptomatic acquired toxoplasmosis. Annals of Internal Medicine. 71, pp. 139-145.

Montoya, J.G. and Liesenfeld, O. (2004). Toxoplasmosis. Lancet. 363, pp. 1965-1976.

Moulin, L., Richard, F., Stefania, S., Goulet, M., Gosselin, S., Goncalves, A. et al. (2010). Contribution of treated wastewater to the microbiological quality of Seine River in Paris. Water Research. 44, pp. 5222-5231.

Munoz-Zanzi, C.A., Fry, P., Lesina, B. and Hill, D. (2010). Toxoplasma gondii oocyst-specific antibodies and source of infection. Emerging Infectious Diseases. 16, pp. 1591-1593.

Nagel, S.D. and Boothroyd, J.C. (1989). The major surface antigen, P30, of Toxoplasma gondii is anchored by a glycolipid. Journal of Biological Chemistry. 264, pp. 5569-5574.

Niedelman, W., Gold, D.A., Rosowski, E.E., Sprokholt, J.K., Lim, D., A Arenas, F. et al. (2012). The rhoptry proteins ROP18 and ROP5 mediate Toxoplasma gondii evasion of the murine, but not the human, interferon-gamma response. 8, pp. e1002784.

Ogunmodede, F., Scheftel, J., Jones, J.L. and Lynfield, R. (2005). Toxoplasmosis prevention knowledge among pregnant women in Minnesota. Minnesota Medical Solutions. 88, pp. 32-34.

Okusaga, O., Langenberg, P., Sleemi, A., Vaswani, D., Giegling, I., Hartmann, A.M. et al. (2011). Toxoplasma gondii antibody titers and history of suicide attempts in patients with schizophrenia. Schizophrenia Research. 133, pp. 150-155.

Olariu, T.R., Remington, J.S., McLeod, R., Alam, A. and Montoya, J.G. (2011). Severe congenital toxoplasmosis in the United States: clinical and serologic findings in untreated infants. The Pediatric Infectious Disease Journal. 30, pp. 1056-1061.

Ong, Y.C., Reese, M.L. and Boothroyd, J.C. (2010). Toxoplasma rhoptry protein 16 (ROP16) subverts host function by direct tyrosine phosphorylation of STAT6. Journal of Biological Chemistry. 285, pp. 28731-28740.

Opsteegh, M., Kortbeek, T.M., Havelaar, A.H. and van der Giessen, J.W. (2015). Intervention strategies to reduce human Toxoplasma gondii disease burden. Clinical Infectious Diseases. 60, pp. 101-107.

Pappas, G., Roussos, N. and Falagas, M.E. (2009). Toxoplasmosis snapshots: global status of Toxoplasma gondii seroprevalence and implications for pregnancy and congenital toxoplasmosis. International Journal of Parasitology. 39, pp. 1385-1394.

Pearce, B.D., Kruszon-Moran, D. and Jones, J.L. (2012). The relationship between Toxoplasma gondii infection and mood disorders in the third National Health and Nutrition Survey. World Journal of Biological Psychiatry. 72, pp. 290-295.

Peixe, R.G., Boechat, M.S., Rangel, A.L., Rosa, R.F., Petzl-Erler, M.L. and Bahia-Oliveira, L.M. (2014). Single nucleotide polymorphisms in the interferon gamma gene are associated with distinct types of retinochoroidal scar lesions presumably caused by Toxoplasma gondii infection. Memorias do Instituto Oswaldo Cruz. 109, pp. 99-107. 
Peixoto-Rangel, A.L., Miller, E.N., Castellucci, L., Jamieson, S.E., Peixe, R.G., Elias, L.S. et al. (2009). Candidate gene analysis of ocular toxoplasmosis in Brazil: evidence for a role for toll-like receptor 9 (TLR9). Memorias do Instituto Oswaldo Cruz. 104, pp. 1187-1190.

Pereboom, M.T., Manniën, J., Spelten, E.R., Schellevis, F.G. and Hutton, E.K. (2013). Observational study to assess pregnant women's knowledge and behaviour to prevent toxoplasmosis, listeriosis and cytomegalovirus. BMC Pregnancy Childbirth. 13, pp. 98.

Pereira-Chioccola, V.L., Vidal, J.E. and Su, C. (2009). Toxoplasma gondii infection and cerebral toxoplasmosis in HIVinfected patients. Future Microbiology. 4, pp. 1363-1379.

Petersen, E., Kijlstra, A. and Stanford, M. (2012). Epidemiology of ocular toxoplasmosis. Ocular Immunology and Inflammation. 20, pp. 68-75.

Peyron, F., Wallon, M., Kieffer, F. and Garweg, J. (2015). Toxoplasmosis. Remington and Klein's Infectious Diseases of the Fetus and Newborn Infant. (Wilson, C.B., Nizet, V., Maldonado, Y.A. and Klein, J.O., ed.). Elsevier BV. Amsterdam. pp. 939-1042.

Pfaff, A.W. and Candolfi, E. (2008). New insights in toxoplasmosis immunology during pregnancy. Perspective for vaccine prevention. Parassitologia. 50, pp. 55-58.

Pfaff, A.W., De-la-Torre, A., Rochet, E., Brunet, J., Sabou, M., Sauer, A. et al. (2014). New clinical and experimental insights into Old World and neotropical ocular toxoplasmosis. International journal for parasitology. 44, pp. 99-107.

Pizzi, H.L., Rico, C.M. and Pessat, O.A.N. (1978). Hallazgo del ciclo ontogenico selvatico del Toxoplasma gondii en felidos salvages (Oncifelis geofroyi, Felis colocolo y Felis eira) de la Provincia de Cordoba. Revista Militar de veterinaria. pp. 293-300.

Prusa, A.R., Kasper, D.C., Pollak, A., Gleiss, A., Waldhoer, T. and Hayde, M. (2015). The Austrian Toxoplasmosis Register, 1992-2008. Clinical Infectious Diseases. 60, pp. e4-e10.

Pusch, L., Romeike, B., Deckert, M. and Mawrin, C. (2009). Persistent toxoplasma bradyzoite cysts in the brain: incidental finding in an immunocompetent patient without evidence of a toxoplasmosis. Clinical neuropathology. 28, pp. 210-212.

Putignani, L., Mancinelli, L., Del Chierico, F., Menichella, D., Adlerstein, D., Angelici, M.C. et al. (2011). Investigation of Toxoplasma gondii presence in farmed shellfish by nested-PCR and real-time PCR fluorescent amplicon generation assay (FLAG). Experimental Parasitology. 127, pp. 409-417.

Rawal, B.D. (1959). Toxoplasmosis; a dye-test survey on sera from vegetarians and meat eaters in Bombay. Transactions of the Royal Society of Tropical Medicine and Hygiene. 53, pp. 61-63.

Remington, J.S. and Cavanaugh, E.N. (1965). Isolation of the encysted form of Toxoplasma gondii from human skeletal muscle and brain. The New England Journal of Medicine. 273, pp. 1308-1310.

Ribeiro, L.A., Santos, L.K., Brito, P.A., Maciel, B.M., Da Silva, A.V. and Albuquerque, G.R. (2015). Detection of Toxoplasma gondii DNA in Brazilian oysters (Crassostrea rhizophorae). Genetics and Molecular Research. 14, pp. 4658-4665.

Robert-Gangneux, F. and Dardé, M.L. (2012). Epidemiology of and diagnostic strategies for toxoplasmosis. Clinical Microbiology Reviews. 25, pp. 264-296.

Roos, D.S., Crawford, M.J., Donald, R.G., Kissinger, J.C., Klimczak, L.J. and Striepen, B. (1999). Origin, targeting, and function of the apicomplexan plastid. Current Opinion in Microbiology. 2, pp. 426-432.

Rosso, F., Les, J.T., Agudelo, A., Villalobos, C., Chaves, J.A., Tunubala, G.A. et al. (2008). Prevalence of infection with Toxoplasma gondii among pregnant women in Cali, Colombia, South America. The American Journal of Tropical Medicine and Hygiene. 78, pp. 504-508.

Rudzinski, M., Meyer, A., Khoury, M. and Couto, C. (2013). Is reactivation of toxoplasmic retinochoroiditis associated to 
increased annual rainfall. Parasite. 20, pp. 44.

Ruiz, A., Frenkel, J.K. and Cerdas, L. (1973). Isolation of Toxoplasma from soil. Journal of Parasitology. 59, pp. $204-206$.

Sánchez, V., De-la-Torre, A. and Gómez-Marín, J.E. (2014). Characterization of ROP18 alleles in human toxoplasmosis. International Journal for Parasitology. 63, pp. 463-469.

Saeij, J.P., Boyle, J.P., Coller, S., Taylor, S., Sibley, L.D., Brooke-Powell, E.T. et al. (2006). Polymorphic secreted kinases are key virulence factors in toxoplasmosis. Science. 314, pp. 1780-1783.

Sagel, U., Mikolajczyk, R.T. and Krämer, A. (2010). Seasonal trends in acute toxoplasmosis in pregnancy in the federal state of Upper Austria. Clinical Microbiology and Infection. 16, pp. 515-517.

Santana, S.S., Gebrim, L.C., Carvalho, F.R., Barros, H.S., Barros, P.C., Pajuaba, A.C. et al. (2015). CCp5A Protein from Toxoplasma gondii as a Serological Marker of Oocyst-driven Infections in Humans and Domestic Animals. Frontiers in Microbiology. 6, pp. 1305.

Santos, TR.dos, Nunes, C.M., Luvizotto, M.C.R., de Moura, A.B., Lopes, W.D.Z., da Costa, A.J. et al. (2010). Detection of Toxoplasma gondii oocysts in environmental samples from public schools. Veterinary Parasitology. 171, pp. 53-57.

Schares, G., Ziller, M., Herrmann, D.C., Globokar, M.V., Pantchev, N. and Conraths, F.J. (2016). Seasonality in the proportions of domestic cats shedding Toxoplasma gondii or Hammondia hammondi oocysts is associated with climatic factors. International Journal for Parasitology. 46, pp. 263-273.

Shapiro, K., Conrad, P.A., Mazet, J.A.K., Wallender, W.W., Miller, W.A. and Largier, J.L. (2010). Effect of estuarine wetland degradation on transport of Toxoplasma gondii surrogates from land to sea. Applied and Environmental Microbiology. 76, pp. 6821-6828.

Shapiro, K., Mazet, J.A.K., Schriewer, A., Wuertz, S., Fritz, H., Miller, W.A. et al. (2010). Detection of Toxoplasma gondii oocysts and surrogate microspheres in water using ultrafiltration and capsule filtration. Water Research. 44, pp. 893-903.

Shapiro, K., VanWormer, E., Aguilar, B. and Conrad, P.A. (2015). Surveillance for Toxoplasma gondii in California mussels (Mytilus californianus) reveals transmission of atypical genotypes from land to sea. Environmental microbiology. 17, pp. 4177-4188.

Shibre, T., Alem, A., Abdulahi, A., Araya, M., Beyero, T., Medhin, G. et al. (2010). Trimethoprim as adjuvant treatment in schizophrenia: a double-blind, randomized, placebo-controlled clinical trial. Schizophr Res. 36, pp. 846-851.

Sibley, L.D. and Ajioka, J.W. (2008). Population structure of Toxoplasma gondii: clonal expansion driven by infrequent recombination and selective sweeps. Annual Review of Microbiology. 62, pp. 329-351.

Slifko, T.R., Smith, H.V. and Rose, J.B. (2000). Emerging parasite zoonoses associated with water and food. International Journal of Parasitology. 30, pp. 1379-1393.

Sotiriadou, I. and Karanis, P. (2008). Evaluation of loop-mediated isothermal amplification for detection of Toxoplasma gondii in water samples and comparative findings by polymerase chain reaction and immunofluorescence test (IFT). Diagnostic Microbiology and Infectious Disease. 62, pp. 357-365.

Sroka, J., Wojcik-Fatla, A. and Dutkiewicz, J. (2006). Occurrence of Toxoplasma gondii in water from wells located on farms. Annals of Agricultural and Environmental Medicine. 13, pp. 169-175.

Staggs, S.E., Keely, S.P., Ware, M.W., Schable, N., See, M.J., Gregorio, D. et al. (2015). The development and implementation of a method using blue mussels (Mytilus spp.) as biosentinels of Cryptosporidium spp. and Toxoplasma gondii contamination in marine aquatic environments. Parasitol Res. 114, pp. 4655-4667.

Su, C., Khan, A., Zhou, P., Majumdar, D., Ajzenberg, D., Dardé, M. et al. (2012). Globally diverse Toxoplasma gondii isolates comprise six major clades originating from a small number of distinct ancestral lineages. Proceedings of the National Academy of Sciences of the United States of America. 109(15), pp. 5849. doi: 10.1073/pnas.1203190109. 
Sullivan, W.J. and Jeffers, V. (2012). Mechanisms of Toxoplasma gondii persistence and latency. FEMS Microbiology Reviews. 36, pp. 717-733.

Suzuki, Y. (2002). Immunopathogenesis of cerebral toxoplasmosis. The Journal of Infectious Diseases. 186 Suppl, pp. S234-S240.

Tavalla, M., Oormazdi, H., Akhlaghi, L., Shojaee, S., Razmjou, E., Hadighi, R. et al. (2013). Genotyping of Toxoplasma gondii Isolates from Soil Samples in Tehran, Iran. Iranian Journal of Parasitology. 8, pp. 227-233.

Tenter, A.M., Heckeroth, A.R. and Weiss, L.M. (2000). Toxoplasma gondii: from animals to humans. Journal of Parasitology. 30, pp. 1217-1258.

Thiébaut, R., Leproust, S., Chêne, G., Gilbert, R. and,. (2007). Effectiveness of prenatal treatment for congenital toxoplasmosis: a meta-analysis of individual patients' data. Lancet. 369, pp. 115-122.

Tizard, I.R., FIsh, A. and Quinn, J.P. (1976). Some observations on the epidemiology of toxoplasmosis in Canada. Journal of Hygiene. 77, pp. 11-21.

Torgerson, P.R. and Mastroiacovo, P. (2013). The global burden of congenital toxoplasmosis: a systematic review. Bulletin of the World Health Organization. 91, pp. 501-508.

Torres-Morales, E., Taborda, L., Cardona, N., De-la-Torre, A., Sepulveda-Arias, J.C., Patarroyo, M.A. et al. (2014). Th1 and Th2 immune response to P30 and ROP18 peptides in human toxoplasmosis. Medical Microbiology and Immunology. 203, pp. 315-322.

Torrey, E.F. and Yolken, R.H. (2007). Schizophrenia and toxoplasmosis. Schizophrenia Research. 33, pp. 727-728.

Triviño-Valencia, J., Lora, F., Zuluaga, J.D. and Gómez-Marín, J.E. (2016). Detection by PCR of pathogenic protozoa in raw and drinkable water samples in Colombia. Parasitology Research.

UEPA (1989). Technical Support document for pathogen reduction in sewagw sludge. National Technical Information Service. Springfield, VA.

Valdès, V., Legagneur, H., Watrin, V., Paris, L. and Hascoët, J.M. (2011). Congenital toxoplasmosis due to maternal reinfection during pregnancy. Archives de Pédiatrie. 18, pp. 761-763.

VanWormer, E., Conrad, P.A., Miller, M.A., Melli, A.C., Carpenter, T.E. and Mazet, J.A.K. (2013). Toxoplasma gondii, Source to Sea: Higher Contribution of Domestic Felids to Terrestrial Parasite Loading Despite Lower Infection Prevalence. Ecohealth. 10, pp. 277-289.

VanWormer, E., Fritz, H., Shapiro, K., Mazet, J.A. and Conrad, P.A. (2013). Molecules to modeling: Toxoplasma gondii oocysts at the human-animal-environment interface. Comparative Immunology, Microbiology and Infectious Diseases. 36, pp. 217-231.

VanWormer, E. (2012). Toxoplasma gondii at the human-animal-environment interface in coastal California: A One Health approach to evaluating land to sea pathogen pollution. unpublished thesis University of California, Davis, doctoral dissertation.

Vargas-Villavicencio, J.A., Besné-Mérida, A. and Correa, D. (2016). Vertical transmission and fetal damage in animal models of congenital toxoplasmosis: A systematic review. Veterinary Parasitology. 223, pp. 195-204.

Verant, M.L., D'Ozouville, N., Parker, P.G., Shapiro, K., VanWormer, E. and Deem, S.L. (2014). Attempted detection of Toxoplasma gondii oocysts in environmental waters using a simple approach to evaluate the potential for waterborne transmission in the Galapagos Islands, Ecuador. Ecohealth. 11, pp. 207-214.

Vidal, J.E., Hernandez, A.V., de Oliveira, A.C., Dauar, R.F., Barbosa, S.P. and Focaccia, R. (2005). Cerebral toxoplasmosis in HIV-positive patients in Brazil: clinical features and predictors of treatment response in the HAART era. AIDS Patient Care STDS. 19, pp. 626-634. 
Vieira, F.P., Alves, M.G., Martins, L.M., Rangel, A.L., Dubey, J.P., Hill, D. et al. (2015). Waterborne toxoplasmosis investigated and analysed under hydrogeological assessment: new data and perspectives for further research. Memorias do Instituto Oswaldo Cruz. 110, pp. 929-935.

Villena, I., Aubert, D., Gomis, P., Ferte, H., Inglard, J.C., Denis-Bisiaux, H. et al. (2004). Evaluation of a strategy for Toxoplasma gondii oocyst detection in water. Applied and Environmental Microbiology. 70, pp. 4035-4039.

Vyas, A., Kim, S.K. and Sapolsky, R.M. (2007). The effects of toxoplasma infection on rodent behavior are dependent on dose of the stimulus. Neuroscience. 148, pp. 342-348.

Wainwright, K.E., Lagunas-Solar, M., Miller, M.A., Barr, B.C., Gardner, I.A., Pina, C. et al. (2007). Physical inactivation of Toxoplasma gondii oocysts in water. Applied and Environmental Microbiology. 73, pp. 5663-5666.

Wainwright, K.E., Miller, M.A., Barr, B.C., Gardner, I.A., Melli, A.C., Essert, T. et al. (2007). Chemical inactivation of Toxoplasma gondii oocysts in water. Journal of Parasitology. 93, pp. 925-931.

Wallace, G.D. (1973). Intermediate and transport hosts in the natural history of Toxoplasma gondii. The American Journal of Tropical Medicine and Hygiene. 22, pp. 456-464.

Wallon, M., Peyron, F., Cornu, C., Vinault, S., Abrahamowicz, M., Kopp, C.B. et al. (2013). Congenital toxoplasma infection: monthly prenatal screening decreases transmission rate and improves clinical outcome at age 3 years. Clinical Infectious Diseases. 56, pp. 1223-1231.

Ware, M.W., Augustine, S.A., Erisman, D.O., See, M.J., Wymer, L., Hayes, S.L. et al. (2010). Determining UV inactivation of Toxoplasma gondii oocysts by using cell culture and a mouse bioassay. Applied and Environmental Microbiology. 76, pp. 5140-5147.

Wechsler, B., D Huong, L.Thi, Vignes, B., Piette, J.C., Chomette, G. and Godeau, P. (1986). Toxoplasmosis and lupus. A review of the literature apropos of 4 cases. Annales de Médecine Interne. 137, pp. 324-330.

Weinman, D. and Chandler, A.H. (1954). Toxoplasmosis in swine and rodents; reciprocal oral infection and potential human hazard. Experimental Biology and Medicine. 87, pp. 211-216.

Weiss, L.M. and Kim, K. (2000). The development and biology of bradyzoites of Toxoplasma gondii. Frontiers in Bioscience. 5, pp. D391-D405.

Wells, B., Shaw, H., Innocent, G., Guido, S., Hotchkiss, E., Parigi, M. et al. (2015). Molecular detection of Toxoplasma gondii in water samples from Scotland and a comparison between the 529bp real-time PCR and ITS1 nested PCR. Water Research. 87, pp. 175-181.

WHO,. (2015). Estimates the Global Burden of foodborne diseases. WHO Foodborne disease burdem epidemiology reference group. Genevo.

Wilson, D.C., Grotenbreg, G.M., Liu, K., Zhao, Y., Frickel, E.M., Gubbels, M.J. et al. (2010). Differential regulation of effector- and central-memory responses to Toxoplasma gondii Infection by IL-12 revealed by tracking of Tgd057-specific CD8+ T cells. PLoS Pathogens. 6, pp. e1000815.

Wong, S.Y. and Remington, J.S. (1993). Biology of Toxoplasma gondii. AIDS. 7, pp. 299-316.

Yang, W.L., Lindquist, H.D.A., Cama, V., Schaefer, F.W., Villegas, E., Fayer, R. et al. (2009). Detection of Toxoplasma gondii Oocysts in Water Sample Concentrates by Real-Time PCR. Applied and Environmental Microbiology. 75, pp. 3477-3483.

Yang, Z., Cho, P.Y., Ahn, S.K., Ahn, H.J., Kim, T.S., Chong, C.K. et al. (2012). A surge in the seroprevalence of toxoplasmosis among the residents of islands in Gangwha-gun, Incheon, Korea. Korean Journal of Parasitology. 50, pp. 191-197.

Yilmaz, S.M. and Hopkins, S.H. (1972). Effects of different conditions on duration of infectivity of Toxoplasma gondii 
oocysts. Journal of Parasitology. 58, pp. 938-939.

Yongabi, K.A. (2015). Biocoagulants for Water and Waste Water Purification: a Review. International Review of Biophysical Chemistry (IREBIC).

Yongabi, K.A. and Knoll, L. (2015). A biocoagulant slow sand filtration for disinfection of Toxoplasma gondii oocysts from Mezam River in Bamenda, Cameroon. African Journal of Biotechnology. 14, pp. 937-943.

Zhang, M., Yang, Z., Wang, S., Tao, L.F., Xu, L.X., Yan, R.F. et al. (2014). Detection of Toxoplasma gondii in shellfish and fish in parts of China. Veterinary Parasitology. 200, pp. 85-89.

Zhang, N.Z., Chen, J., Wang, M., Petersen, E. and Zhu, X.Q. (2013). Vaccines against Toxoplasma gondii: new developments and perspectives. Expert Review of Vaccines. 12, pp. 1287-1299.

Zhou, P., Chen, Z., Li, H.L., Zheng, H., He, S., Lin, R.Q. et al. (2011). Toxoplasma gondii infection in humans in China. Parasites and Vectors. 4, pp. 165.

Zuber, P. and Jacquier, P. (1995). Epidemiology of toxoplasmosis: worldwide status. Schweizerische medizinische Wochenschrift Supplementum. 65, pp. 19S-22S.

Zulpo, D.L., Headley, S.A., Biazzono, L., da Cunha, I.A., Igarashi, M., de Barros, L.D. et al. (2012). Oocyst shedding in cats vaccinated by the nasal and rectal routes with crude rhoptry proteins of Toxoplasma gondii. Experimental Parasitology. 131, pp. 223-230. 